\title{
Pathways of Intraseasonal Variability in the Indonesian Throughflow Region
}

\author{
A. Schiller , S. E. Wijffels ${ }^{1}$, J. Sprintall , R. Molcard ${ }^{3}$ and P. R. Oke ${ }^{1}$
}

Centre for Australian Weather and Climate Research - A partnership between CSIRO and the Bureau of Meteorology; CSIRO Wealth from Oceans National Research Flagship, Hobart, Tasmania, Australia.

2 Scripps Institution of Oceanography, University of California San Diego, La Jolla, California, USA 3

Laboratoire d'Oceanographie et du Climat: Experimentation et Approaches Numeriques, Université Pierre et Marie Curie, Paris, France

Corresponding Author: A. Schiller, CSIRO Marine and Atmospheric Research, Castray Esplanade, GPO Box 1538, Hobart 7001, Tasmania, Australia (andreas.schiller@csiro.au) 


\begin{abstract}
The recent INSTANT measurements in the Indonesian archipelago revealed a broad spectrum of time scales that influence Throughflow variability, from intraseasonal (20-90 days) to interannual. The different time scales are visible in all transport and property fluxes and are the result of remote forcing by both the Pacific and Indian Ocean winds, and local forcing generated within the regional Indonesian seas. This study focuses on the time-dependent three-dimensional intraseasonal variability (ISV) in the Indonesian Throughflow (ITF) region, in particular at the locations of the INSTANT moorings at the Straits of Lombok, Ombai and Timor. The Bluelink ocean reanalysis in combination with the observations from the INSTANT observing program reveals that deep-reaching sub-surface ISV in the eastern Indian Ocean and ITF is closely linked with equatorial wind-stress anomalies in the central Indian Ocean. Having travelled more than $5000 \mathrm{~km}$ in about 14 days, the associated Kelvin waves can be detected as far east as the Banda Sea. ISV near the Straits of Ombai and Timor is also significantly influenced by local wind forcing from within the ITF region. At the INSTANT mooring sites the ocean reanalysis agrees reasonably well with the observations. Intraseasonal amplitudes are about $\pm 1.0{ }^{\circ} \mathrm{C}$ and $\pm 0.5 \mathrm{~m} / \mathrm{s}$ for potential temperature and velocity anomalies. Associated phases of ISV are very similar in observations and the reanalysis. Where differences exist they can be traced backed to likely deficits in the reanalysis, namely the lack of tidal dissipation, insufficient spatial resolution or errors in surface forcing.
\end{abstract}

Keywords: Indonesian Throughflow, Indian Ocean, intraseasonal variability, ocean reanalysis, INSTANT program, Kelvin waves, Rossby waves. 


\section{Introduction}

The Indonesian Throughflow (ITF) is an integral part of the global climate system and thermohaline circulation (e.g., Gordon and Susanto, 2001), providing a low-latitude pathway for the transfer of warm, low salinity Pacific waters into the Indian Ocean. The heat and freshwater carried by the ITF impacts the basin budgets of both the Pacific and the Indian Oceans [Wijffels et al., 2002]. Within the internal Indonesian Seas, observations and models indicate that the primary ITF source is North Pacific thermocline water flowing through Makassar Strait (sill depth 650 m, 'M' in Fig. 1). Additional ITF contributions of lower thermocline water and deep water masses of direct South Pacific origin are derived through the eastern routes, via the Maluku and Halmahera Seas, with dense water overflow at the Lifamatola Passage (sill depth 1940 m). The ITF exits into the eastern Indian Ocean through the major passages along the Lesser Sunda Island chain: Ombai Strait (sill depth 3250 m, 'O' in Fig.1), Lombok Strait (300 m, 'L' in Fig. 1), and Timor Passage (1890 m, ' $\mathrm{T}$ ' in Fig. 1). The complex geography of the region, with multiple narrow constrictions connecting a series of large, deep basins, leads to a circuitous ITF pathway within the Indonesian seas. En route the Pacific inflow waters are modified due to mixing, upwelling and air-sea fluxes before being exported to the Indian Ocean [KochLarrouy et al., 2007].

To help fully resolve the temporal variability and characteristics of the ITF transport and property fluxes, a multi-year comprehensive measurement program was required. The INSTANT program addressed these requirements [Gordon et al., 2008; Sprintall et al., 2009]. An international co-operative effort to directly and simultaneously measure Throughflow velocity, salinity and temperature in the major passages, INSTANT moorings were deployed from January 2004 to December 2006 in Makassar Strait, Lifamatola Passage, Lombok Strait, Ombai Strait and Timor Passage (Table 1). INSTANT provided a time series of ITF transport and property fluxes, and their variability from intraseasonal to annual time scales, along the ITF pathway from the intake of Pacific water at Makassar Strait and 
Lifamatola Passage, to the Lesser Sunda exit channels into the Indian Ocean. The resulting simultaneous, multi-year direct measurements in both the inflow and outflow ITF passages allow, for the first time, to unambiguously determine the magnitude of inter-ocean transport and its properties on intraseasonal to interannual timescales [Gordon et al, 2008; Sprintall et al, 2009].

The potential predictability of ocean dynamics in the proximity of the ITF has attracted considerable interest in recent years [Qiu et al., 1999; Chong et al., 2000; Potemra et al., 2002; Syamsudin et al., 2004; Wijffels and Meyers, 2004; Iskandar et al., 2005, 2006; Yu and Potemra, 2006; Atmadipoera et al., 2009]. For example, Wijffels and Meyers [2004] explored observation-based temperature and sea level variability within the Indonesian seas and southeast Indian Ocean. A lagged partial regression technique revealed that on interannual timescales anomalies from a mean seasonal cycle of temperature and sea level on seasonal-to-interannual time scales can be largely understood in terms of free Kelvin and Rossby waves generated by remote zonal winds along the equator of the Indian and Pacific Oceans, with local wind forcing appearing to play a minor role. About $60-90 \%$ of interannual sea level variability and $70 \%$ of thermocline temperature variability can be accounted for in this way. Variations in zonal Pacific equatorial winds force a response along the Arafura/Australia shelf break through Pacific equatorial Rossby waves exciting coastally trapped waves off the western tip of New Guinea that propagate poleward along the Australian west coast. The signature of this Pacific energy radiating westward across the Banda Sea and into the subtropical south Indian Ocean within $1500 \mathrm{~km}$ of the coast is also prevalent. Equatorial Indian Ocean wind energy propagates along the Sumatra-Java-Nusa Tenggara waveguide to penetrate the Savu Sea, the western Banda Sea and Makassar Strait, thus having an impact on the western internal seas. Hence the region comprises the intersection of two ocean waveguides, as first predicted by Clarke and Liu [1994] and explored more recently by Wijffels and Meyers [2004].

Various research teams have employed high-resolution ocean general circulation models to investigate 
dynamics of intraseasonal variability in surface and subsurface currents off Java. For instance, the results of Iskandar et al. [2006] indicate that the surface current, the so-called South Java Coastal Current (SJCC), is dominated by variations with a period of 90 days. In the subsurface current, which is referred to as the South Java Coastal Undercurrent (SJCU), 60-day variations are the most prominent feature. The 90-day variations in the SJCC captured mostly by the first baroclinic mode are found to be primarily driven by winds. These variations are associated with the propagation of the first baroclinic Kelvin waves generated in the central equatorial Indian Ocean. On the other hand, the 60-day variations in the SJCU are enhanced by wind forcing over the eastern equatorial Indian Ocean off Sumatra and are mostly captured by the second baroclinic mode [Iskandar et al., 2006]. By separately varying winds and transports through individual straits Yu and Potemra [2006] showed that the seasonal cycles of both the wind and the transport through Lombok Strait play crucial roles in generating mixed barotropic and baroclinic instabilities during July -September. Both the spatial and temporal patterns of the variability are also sensitive to transports through Ombai Strait and, to a lesser degree, Timor Passage.

The focus of this study is on investigating local intraseasonal variability (ISV) in the INSTANT observations and, by using output from an eddy-resolving ocean reanalysis, to link this local variability to large-scale ISV. The ocean reanalysis named Bluelink ReANalyis (BRAN Version 2.1) is described in detail in Oke et al. [2008] and Schiller et al. [2008]. Briefly, the MOM4p0 global hydrodynamic model is used [Griffies et al., 2004], with a resolution of (1/10) in the Asian-Australian region. There are 47 levels in the vertical, with $10 \mathrm{~m}$ resolution near the surface. Observations from all available satellite altimeters (ERS, GFO, TOPEX/Poseidon, Envisat and Jason-1), 57 coastal tide gauges around Australia, plus sea surface temperature observations from Pathfinder and AMSR-E satellite missions are assimilated into the model. Observations of in situ temperature and salinity from the Argo, TAO and XBT programs are also assimilated into the model. The model is forced by 6-hourly atmospheric fields from the 40 year reanalysis ERA-40 of the ECMWF (http://data.ecmwf.int/data/d/era40 daily), including 
all surface forcing fields, i.e. wind stresses, heat and freshwater fluxes. From September 2002 onwards (end of ERA-40 period) we use the operational ECMWF products as forcing fields.

Based on the INSTANT experiment and the ocean reanalysis this study investigates the spatial and temporal pattern of remotely forced ISV that originates in the Indian Ocean and locally forced ISV that originates within the Indonesian internal seas. After a brief assessment of the skill of the reanalysis on intraseasonal timescales in section 2, section 3 focuses on the energy propagation along identified ray paths that coincide with the INSTANT moorings at the southern end of the ITF (Table 1). Section 4 provides a synthesis by exploring composites of individual intraseasonal events, and finally the conclusions are presented in Section 5.

\section{Model Skill}

The Bluelink reanalysis and its performance on annual mean, seasonal and event-based time scales have been discussed in various previous publications, e.g. Oke et al. [2008; 2009]; Schiller et al. [2008, 2009]. Here, we provide a brief overview about its performance in the major straits of the Lesser Sunda Islands that link the ITF with the Indian Ocean.

The mean transports into the Indian Ocean over the 3-year INSTANT period in the observations for Lombok Strait, Ombai Strait and Timor Sea are 2.6 Sv, 4.9 Sv and 7.5 Sv, respectively. The corresponding transports from the ocean reanalysis are $3.9 \pm 2.2 \mathrm{~Sv}$ (standard deviation of the daily transport), $4.1 \pm 2.4 \mathrm{~Sv}, 7.8 \pm 2.4 \mathrm{~Sv}$ for Lombok Strait, Ombai Strait and Timor Sea. Thus the reanalysis shows good agreement with the observations for the total mean Throughflow and that in Timor Passage but -as discussed in the text below- an incorrect gating of the mean flow between Lombok and Ombai Strait.

Fig. 2 compares mean and standard deviations of observed and simulated along-strait velocity profiles for INSTANT moorings in Lombok Strait, Ombai Strait and Timor Sea. Although the reanalysis resembles the observations and their variability at the four moorings across the Timor Sea, larger 
differences occur at the moorings of Ombai North and Lombok East and West. For these moorings differences are rather large in the top 200m. In case of Ombai North (Fig. 2e) the mean transport in the reanalysis is towards the Indian Ocean (negative) whereas it is slightly positive in the observations. At both Lombok moorings (Fig. 2g,h) the mean inflows into the Indian Ocean in the reanalysis exceed those of the observations. We speculate that these differences, where the BRAN2.1 Lombok Throughflow and its variability are too strong might be due to unresolved frictional processes in the model such as tidal dissipation and/or the wind forcing being too strong during this period [Schiller et al., 2008].

The flow in Lombok Strait is well documented, largely due to the Lombok Strait Experiment in 1985 [Murray and Arief, 1988]. Flow through the $35 \mathrm{~km}$ wide Lombok Strait is restricted by a sill depth of about $300 \mathrm{~m}$ at the southern end. From February through May 1985, transport through Lombok Strait was only $1 \mathrm{~Sv}$ southward due to discrete occasions of shallow northward flow, compared to $4 \mathrm{~Sv}$ observed during the southeast monsoon from July through September. Similar periods of northward transport were inferred from changes in the cross-strait pressure gradient measured by the shallow pressure gauges deployed across Lombok Strait from 1996-1999 [Hautala et al., 2001]. These reversals of the Throughflow are prevalent in the INSTANT data set (Fig. 3 a,c) in both the Lombok and Ombai Straits and appear reasonably well simulated by BRAN2.1 (Fig. 3 b,d), though the latter features a bias towards stronger and deeper reaching reversal events in Lombok that are likely to be associated with unresolved dissipation in that strait resulting in excessive mean flow. Thus we consider it worthwhile to explore the fully 3- dimensional regional signature of the intraseasonal variability in BRAN2.1.

To focus on the intraseasonal timescale in the subsequent discussion all observational and model data are detrended, de-seasonalised and bandpass-filtered with cut-off periods of 20 and 90 days. 


\section{Three-Dimensional Wave Propagation}

\subsection{Correlations and Ray Paths: Eastern Indian Ocean Wind Forcing}

Remote wind forcing from the Indian Ocean is responsible for changes in the ITF via the generation of equatorial and coastal Kelvin waves. Anomalous wind bursts in the equatorial Indian Ocean force an equatorial Kelvin wave that, upon impinging on the west coast of Sumatra, causes poleward propagating coastal Kelvin waves. Westerly wind bursts force downwelling Kelvin waves semi-annually during the monsoon transitions, nominally in May and November, and intraseasonally in response to, e.g., the Madden-Julian Oscillation [Madden and Julian, 1971]. The poleward propagation of the downwelling coastal Kelvin wave raises the sea level along the Indonesian wave guide of Sumatra and the Lesser Sunda Islands [Clarke and Liu, 1993, 1994], causes maximum eastward flow of the semi-annually reversing South Java Current [Quadfasel and Cresswell, 1992], and may temporarily reverse the alongstrait pressure gradient within the Lesser Sunda passages [Hautala et al., 2001]. In May 1997, a semiannually forced Kelvin wave resulted in eastward flow of very fresh, warm water in the South Java Current [Sprintall et al., 1999], with subsequent northward flow observed up through Lombok Strait and past a mooring in Makassar Strait [Sprintall et al., 2000].

An analysis of the intraseasonal zonal wind variance [Large and Yeager, 2004] in the Indian Ocean shows that the strongest variance occurs in the central and eastern near-equatorial region (not shown) and that the zonal scale of the intraseasonal winds are large, typically spanning about $20^{\circ}$ of longitude. We thus form a wind index averaged in this region (Fig. 1). Lagged correlations of our eastern Indian equatorial wind index with intraseasonal sea-level anomalies in the Indo-Pacific region (Fig. 4) shows the generation of an equatorial downwelling (high sea level) Kelvin Wave in the Indian Ocean which, upon reaching Sumatra, propagates poleward in the coastal waveguide (lags 0 and -7 days) - which is well simulated in by BRAN2.1. At the same time, the westerly windbursts excite an upwelling Rossby Wave (low sea level) which can be seen to travel westward near $5^{\circ} \mathrm{N}$ and $5^{\circ} \mathrm{S}$. During the next two 
weeks the northern downwelling coastal Kelvin wave travels around the Bay of Bengal and the southern branch enters the Indonesian archipelago through various straits (lags -14 and -21 days). At the final stages (lags -28 and -35 days) a set of downwelling off-equatorial Rossby Waves separate from the Sumatra coasts and propagate westward, whereas the signal in the Indonesian Archipelago weakens and finally disperses. As the active and quiet phases of the intraseasonal disturbance propagate eastward, the correlations in both the Indian and Pacific Ocean change sign [Schiller and Godfrey, 2003]. The reanalysis captures all of the observed large-scale features (Fig. 4) quite accurately, thus providing further confidence about applying output from the reanalysis to deduce useful information about ISV along characteristic ray paths.

We now investigate major ray paths: the first path starts in the box of equatorial Indian Ocean wind stresses (black box) and continues along the coasts of Sumatra and Java (red line in Fig. 1). Off Lombok Strait the path follows the shelf edge where it meets the Australian Northwest Shelf. Labels E, L, T denote geographical points along this track. Fig. 5 depicts the lagged correlations of potential temperature with Indian Ocean wind stress in the upper $1500 \mathrm{~m}$ of the water column along this path. The along-track penetration of the signal is clearly visible and correlations locally reach 0.6 at thermocline depth (Fig. 5d). Beyond Lombok Strait (label 'L') and then again beyond Timor Strait (label 'T') the correlations weaken in the upper 500m that energy is redirected away from this path into the Flores (via Lombok), Savu (towards Ombai Strait), and Timor Seas (see below). Note the drop in correlation above 1000m just past Lombok ('L' in Fig. 5) along this path confirming that the shallow intraseasonal energy has passed into the Savu Sea (sill $\sim 800-1000 \mathrm{~m}$ ) and it is only the energy at deeper levels that continues to propagate towards Timor Passage and along to the Australian Northwest Shelf. Upward phase propagation is apparent, consistent with free downward propagating long linear planetary waves - the downward energy propagation is seen in the increase in correlations at depth at longer lags.

We calculated the expected group energy ray paths for 60-day free equatorial Kelvin and Rossby 
waves based on linear theory [McCreary, 1984] and BRAN2.1's mean stratification. For linear free waves the phase lines should be parallel to the ray path - a condition that is evident in Fig. $5 \mathrm{f}$ for the free-60 day period Kelvin wave generated near the surface in the eastern equatorial ocean. The ray path of this wave bends down to the east through the thermocline and crosses eastern end of the Timor Passage near $1200 \mathrm{~m}$ depth. The estimated upward phase propagation is about $100 \mathrm{~m} /$ day. Free equatorial Rossby wave ray paths are steeper and westward, matching the phase behaviour we see in BRAN2.1 west of the coast of Sumatra (point 'E' in Fig. 5d).

Part of the wave energy from the Sumatra-Java section follows a path from Lombok Strait northward along the Java Sea shelf break to Makassar Strait (green line in Fig. 1) - we find lag correlations that locally exceed 0.4 in temperature and velocity, diminishing upon reaching the northern Makassar Strait (not shown). Another route taken by the intraseasonal energy excited in the eastern equatorial Indian Ocean is to pass into the Savu Sea and on towards Ombai Strait and the Banda Sea (light blue line in Fig. 1). The correlations indicate an eastward propagating wave in the upper $600 \mathrm{~m}$ of the water column (max. correlation $=0.5)$ but near the surface temperature is uncorrelated with equatorial Indian Ocean wind stress suggesting that local forcing is the dominant influence on mixed layer temperature. The forth energy pathway commences at the INSTANT moorings of the Timor Sea and then follows the Timor Sea via the Arafura Sea to the Banda Sea (yellow line in Fig. 1). The signal appears at the shelf edge between days 5 and 10 at a depth below 500m and gradually propagates eastward and upward (max. correlation $>0.4$ ) before loosing its signature in the Banda Sea.

\subsection{Composite Events: Eastern Indian Ocean Wind Forcing}

To better understand the overarching processes that underlie these correlations we investigate composites of intraseasonal events in the eastern Indian Ocean and connections to the ITF. The composites are calculated by first determining zonal wind stress anomalies in the equatorial box shown in Fig. 1, and subsequently identifying any peaks of intraseasonal events which exceeded plus/minus one 
standard deviation in amplitude. Composites are calculated with day zero representing the peak of zonal wind events in the eastern Indian equatorial box - negative and positive events are separately analysed. This way, we obtained composites based on 35 negative anomaly events (usually characterized by easterly wind burst, Shinoda et al. [1998]) and based on 23 positive anomaly events (usually characterized by westerly wind bursts) during the INSTANT period - January 2003 to December 2006. Note that this definition allows for asymmetry between positive and negative intraseasonal episodes - indeed we note that the positive (westerly) events are strong and short lived while the negative (easterly) events tend to be weak and long lasting.

Fig. 6 shows the evolving temperature anomalies during the negative and positive phases of an intraseasonal oscillation at thermocline depth $(\mathrm{z}=145 \mathrm{~m})$. The gradual increase in negative temperature anomalies over time in Fig. 6a-d is likely to have been caused by stronger easterly wind components that create eastward propagating upwelling Kelvin waves [LeBlond and Mysak, 1978]. Along the equator this negative anomaly propagates eastward until it reaches the coast of Sumatra (Fig. 6a) where it separates into a northward and southward coastal Kelvin Wave (Fig. 6d). The strongest negative anomaly at this depth exists on day 10 off Sumatra (Fig. $6 \mathrm{c}$, about $-1.4^{\circ} \mathrm{C}$ ). At the same time, the southern Kelvin wave has progressed eastward where it first passes Lombok Strait, and remains coherent until it reaches Timor (Fig. 6f, day 25).

A similarly shaped development but with opposite signs emerges for potential temperature at $\mathrm{z}=145 \mathrm{~m}$ from its positive phases of ISV (Fig. 6 h-n). The positive (i.e. westerly) wind anomaly creates a downwelling equatorial and then a coastal Kelvin wave. Maximum positive anomalies are visible around days 5 to 15 (Fig. 6 i-k). Notably, the positive temperature anomalies reach Lombok Strait around day 5 (Fig. 6i) - that is, 5 days earlier than the negative anomalies. There is a clear indication of the positive temperature anomalies penetrating into Makassar Strait. We note that even after the respective peaks there is a weak asymmetry in the negative and positive phases as positive temperature anomalies persist 
even 30 days after the maximum of equatorial wind stress (Fig. 6n) and are still detectable along the Australian Northwest Shelf.

Despite this asymmetry of positive and negative phases, to first order and on larger spatial scales the associated vertical sections of composite potential temperature anomalies along ray paths are approximately of opposite sign. In the subsequent paragraph we therefore restrict our discussion to vertical sections of composite potential temperatures and velocities during the positive phase of ISV. Fig. 7 depicts composites of potential temperature along the ray path from the equatorial Indian Ocean via the Sumatra and Java wave guides towards Australia. The demise of negative temperature anomalies on days -30 to -10 (Fig. 7 b-c) is followed by a strengthening of positive anomalies by day 0 (Fig. 7 d). The positive anomalies gradually propagate south-eastward, reaching their strongest anomaly amplitude with about $2^{\circ} \mathrm{C}$ on day 10 at a depth of $100 \mathrm{~m}$ (Fig. 7e). The anomalies reach their greatest vertical extension on the same day with a subsequently diminishing signal at larger depth, i.e. upward phase propagation (Fig. $7 \mathrm{f}-\mathrm{g}$ ). The associated velocity anomalies (not shown) exhibit less coherent signals with anomalies extending to a larger depth range, both presumably due to the significance of "noisy" barotropic meso-scale eddy fields on the composite data. Along-track intraseasonal velocity anomalies reach amplitudes of about $\pm 0.25 \mathrm{~m} / \mathrm{s}$ along the Sumatra-Java coasts.

Along the Lombok-Makassar Strait section and prior to day 0 intraseasonal along-track velocity anomalies are predominantly negative (Fig. 8a-d). However, these negative temperature anomalies often do not reach the surface, indicating that local processes may dominate intraseasonal variability within the Ekman layer. The positive velocity anomalies arrive at Lombok Strait around day 10 (c.f. Fig. 7) and then slowly progress northward towards Makassar Strait where they remain coherent on day 30 (Fig. 8 g). The associated section of positive potential temperature anomalies (not shown) reach amplitudes of about $0.5^{\circ} \mathrm{C}$ during days 10 and 20 and start to disperse after 30 days.

Figs. 9 and 10 display the composite anomalies of potential temperature and along-track velocity 
along the Lombok-Savu Sea-Ombai Strait-Banda Sea section. During the first phase of the positive composites the upper $500 \mathrm{~m}$ to $1000 \mathrm{~m}$ of the ocean, except the Ekman layer, are characterized by an almost homogeneous negative potential temperature anomaly (Fig. 9 a-d). The positive temperature anomalies arrive on day 10 and exceed $0.8^{\circ} \mathrm{C}$. The waves subsequently propagate eastward through Ombai Strait before reaching the Banda Sea after day 20 (Fig. 9 f). The arrival of the Kelvin wave is evident in the along-track velocities around day 0 (Fig. 10d), and subsequently travels eastward showing signs of upward phase propagation. Interestingly, a relatively strong negative anomaly (about $-0.1 \mathrm{~m} / \mathrm{s}$ ) develops beneath the positive anomalies by day 10 and propagates eastward. The source of this negative anomaly can be traced back to the equatorial region where it emerges at day 0 .

Finally, the corresponding temperature anomalies along the Timor Strait-Banda Sea section (Fig. 11) reveal near-surface features similar to the Lombok-Savu Sea-Ombai Strait-Banda Sea section (Fig. 9) with a transition from negative to positive anomalies. One exception are the amplitudes that are only about half of those of the Lombok-Savu Sea-Ombai Strait-Banda Sea section for both temperature and along-track velocity anomalies (not shown) $\left(0.4{ }^{\circ} \mathrm{C}\right.$ vs. $0.8^{\circ} \mathrm{C}$ and $0.04 \mathrm{~m} / \mathrm{s}$ vs. $\left.0.08 \mathrm{~m} / \mathrm{s}\right)$. This indicates that most of the energy excited in the eastern Indian Ocean passes through Lombok and through Savu Seas, and only a minor component arrives in the Timor Passage in the upper ocean.

Having established a picture of the three-dimensional large-scale propagation of ISV from the Indian Ocean to the ITF we now return to the assessment of local features at the sites of the INSTANT moorings. These mooring sites are chosen because of their complete time series (due to instrument failure other mooring sites of the INSTANT program have significant gaps in the data time series and are therefore not suitable for the assessment of ISV).

Figs. 12 and 13 show composites of the INSTANT mooring at the eastern side of Lombok Strait and the associated output from BRAN2.1. There is good agreement between the model and the observations in terms of the different phases of the positive and negative extremes. We note that near-surface data are 
missing in the temperature observations and the model overestimates the amplitudes compared to the observations for both potential temperature $\left( \pm 1.2^{\circ} \mathrm{C}\right.$ vs. $\left.\pm 0.6^{\circ} \mathrm{C}\right)$ and along-track velocity anomalies $( \pm 0.7 \mathrm{~m} / \mathrm{s}$ vs. $\pm 0.3 \mathrm{~m} / \mathrm{s})$. We also note that the signals have their maxima at or near the surface.

The corresponding Figs. 14 and 15 show the composites of potential temperature and along-track velocity anomalies at the mooring south of Ombai Strait. Here, the vertical structure of anomalies is more complex as is the temporal evolution of the signals. For example, Fig. 14a shows a patch of persistent positive temperature anomalies below 500m in BRAN2.1 that is not evident in the corresponding INSTANT observations (Fig. 14b). Furthermore, the velocity signals in BRAN2.1 clearly underestimate the observed amplitudes.

Finally, Figs. 16 and 17 show the composite anomalies at the mooring location off Timor Roti. There is good agreement in amplitudes and phases between model and observations for potential temperature (Fig. 16) but less so in the details of the (generally weak) velocity amplitudes (Fig. 17). Overall, BRAN2.1 intraseasonal variability excited in the eastern Indian Ocean is too strong in Lombok and too weak in Ombai, suggesting that too much intraseasonal energy passes northward into Lombok than passes east to Ombai compared to the observations that indicate that about equal energy ends up in Lombok and Ombai. Both BRAN2.1 and INSTANT confirm that some Indian Ocean intraseasonal energy arrives in Timor Passage but that it is a weak effect.

\subsection{Composite Events: Banda Sea Wind Forcing}

The previous sections focused on the propagation of ISV from the equatorial Indian Ocean into the ITF via the Straits of Lombok, Ombai and Timor. Here, we assess the impact of local intraseasonal wind stress anomalies (brown box in Fig. 1) on the variability along the Straits. The composites were calculated in a way similar to the composites relative to the equatorial Indian Ocean (see 3.2) but here we use wind stress over the ITF box to define the time lags. Fig. 18 shows sequences of the zonal and meridional velocity anomalies at a depth of $5 \mathrm{~m}$ relative to the peak of positive wind stress anomalies in 
the ITF. As expected, the response to the zonal intraseasonal forcing appears initially as an immediate broadscale downwind response over the region but with an enhanced strong signal off the Java coast (Fig. $18 \mathrm{a}-\mathrm{g}$ ). This response tapers off over 5-10 day lags. As the atmospheric intraseasonal disturbance continues its path eastward, the near surface temperature anomalies in the area of the Indonesian archipelago gradually change signs from positive to negative.

Composites of the meridional surface velocity anomaly (Fig. 18 h-n) show similar large-scale pattern to the zonal velocity anomalies, but the strongest response is nearer 5 days - consonant with a rotation to the right of the wind over the inertial response time of around 3-5days in this region. However, the most striking feature of the meridional velocity anomalies is a strong northward anomaly appearing from Lombok through Makassar Straits between days 5 and 10 (Fig. 18 h,i), with magnitudes that exceed 0.4 $\mathrm{m} / \mathrm{s}$ and can be followed up to the Celebes Sea. Thus local westerly wind bursts retard the shallow Makassar/Lombok ITF and may be responsible for driving a reversal of the shear in the mean ITF as the positive wind events tend to be stronger than the negative events.

Finally, we compare observed and simulated composites of anomalies of potential temperature and along-track velocities at the mooring locations relative to peak wind stress anomalies in the ITF (Figs. 19 and 20). Although there are some similarities to the corresponding Figs 14 and 16 relative to the equatorial Indian Ocean wind stress anomalies some (expected) differences also exist, e.g. in the earlier arrival of anomalies due to ITF forcing relative to equatorial Indian Ocean forcing. Another noteworthy difference exists in Ombai Strait (Fig. 19). Here, the time-depth signal of potential temperature anomalies has larger amplitudes in the thermocline $\left( \pm 0.6^{\circ} \mathrm{C}\right)$ than those associated with the equatorial Indian Ocean (Fig. 14, $\pm 0.3^{\circ} \mathrm{C}$ ). This difference is highlighted in the reanalysis in the upper $200 \mathrm{~m}$ (observations are missing here), indicating a larger impact of the regional ITF forcing on ISV in Ombai Strait compared to the impact of remote forcing from the equatorial Indian Ocean in BRAN2.1.

At Timor Roti (Fig. 20) there is reasonable agreement in the time-depth structure of potential 
temperature between observations (Fig. 20 b,d) and reanalysis (Fig. 20 a,c). Quite interestingly, in the reanalysis the composites of negative events of Timor Roti (Fig. 20c), as well as those of Ombai Strait (Fig. 19c), show strong negative temperature anomalies below the Ekman layer during and after the intraseasonal signal has passed through the region (days 0 to 30). Such strong negative signals are missing in the corresponding figures of composites with equatorial wind stress anomalies (Figs. 14c and 16c), again indicating the combined effect of remote and regional forcing on ISV in the ITF. The dynamics of this deeper temperature response to the local intraseasonal forcing merits further investigation.

\section{Concluding Remarks}

In this paper we present results from a combined analysis of observations from the INSTANT mooring program and the Bluelink ocean reanalysis (BRAN2.1) in the Indonesian archipelago. The observations from the INSTANT program have proven to be a valuable data set to evaluate BRAN2.1 on intraseasonal time scales. Conversely, the eddy-permitting ocean reanalysis has enabled us to extrapolate the point-measurements of the INSTANT moorings to the three-dimensional large-scale circulation.

On the short time scales of ISV (20 to 90 days) the ITF clearly responds to both remote as well as local forcing and the reanalysis captures many of the observed features in terms of amplitudes and phases of ISV. Both the Bluelink reanalysis and the observations from the INSTANT observing program reveal that ISV reaches depths of more than $1000 \mathrm{~m}$ in the eastern Indian Ocean and reaches bottom depths at the mooring sites of the lesser Sunda Straits and Timor Sea. Associated intraseasonal amplitudes are about $\pm 1.0^{\circ} \mathrm{C}$ and $\pm 0.5 \mathrm{~m} / \mathrm{s}$ for potential temperature and velocity anomalies. Kelvin waves that originate from equatorial Rossby waves in the Indian Ocean are detected as far east as the Banda Sea after having travelled more than $5000 \mathrm{~km}$ over 14 days. ISV near the Straits of Ombai and Timor is also significantly influenced by local wind forcing from within the ITF. 
The propagation and scattering of the intraseasonal wave energy excited in the equatorial eastern Indian Ocean appears to qualitatively follow linear wave theory with the group energy penetrating downward along ray paths consonant with long free waves and with an associated upward propagation of phase. Thus in the Lombok and Ombai Straits the deep temperature and velocity responses on intraseasonal timescales are dominated by the Indian Ocean wind energy, while the near surface response is dominated by local intraseasonal wind generating an Ekman-like response (with a 2-5 day inertial lag in velocity). There is a fascinating deeper temperature response to local Banda Sea wind bursts as well as a strong northward jet from Lombok through Makassar Strait that is excited. The effect of these responses plus the asymmetry in the wind forcing itself (short strong westerly wind bursts versus weaker longer-lasting easterly winds) may leave an imprint on the shear of the mean ITF. There are some notable discrepancies between the reanalysis and the observations. The mean and standard deviation of the model results in Lombok Strait (Fig. 2) significantly deviate from the INSTANT observations. In the reanalysis the Indian Ocean driven ISV overestimates the amplitudes at the Lombok Strait mooring (Figs. 12 and 13), whereas at Ombai Strait the reanalysis underestimates amplitudes (Figs. 14 and 15). Together, these discrepancies suggest that in the reanalysis too much wave energy from the Indian Ocean passes through Lombok Strait up to Makassar Strait rather than 'jumping' the strait and following the coastal wave guide to Ombai Strait. Most likely, the main reasons for this discrepancy can be found in a combination of some or all of the subsequent shortcomings: a lack of tidal dissipation in the model (Lombok Strait), a relatively coarse or inaccurate bathymetry through Ombai Strait, and/or some possible deficiencies in the wind stress forcing applied to the reanalysis. This recognition provides guidance for future developments of the Bluelink system. Of the remaining wave energy that emanates from the equatorial Indian Ocean relative little (but not negligible) of the original signal arrives at the Australian Northwest Shelf or propagates through Timor Strait into the Banda Sea. 


\section{Acknowledgements}

Financial support for this research is provided by CSIRO, the Bureau of Meteorology, and the Royal Australian Navy as part of the project Bluelink -Ocean Forecasting Australia and the international INSTANT program. Satellite altimetry is provided by NASA, NOAA, and CNES. SST observations are provided by NOAA and Remote Sensing Systems. Rebecca Cowley processed the data and provided the figures. The authors also acknowledge the many contributions of the Bluelink science team. Rebecca Cowley processed many of the observational data. Her help in plotting of the data from the INSTANT program is greatly appreciated. 


\section{References}

Atmadipoera, A., R. Molcard, G. Madec, S. Wijffels, J. Sprintall, A. Koch-Larrouy, I. Jaya, and A. Supangat, 2009. Characteristics and variability of the Indonesian throughflow water at the outflow straits, Deep Sea Res. I, 56, doi:10.1016/j.dsr.2009.06.004.

Chong, J. C., J. Sprintall, S. Hautala, W. L. Morawitz, N. A. Bray, and W. Pandoe, 2000. Shallow throughflow variability in the outflow straits of Indonesia. Geophys. Res. Let., 27, 125-128.

Clarke, A. J., and X. Liu, 1993. Observations and dynamics of semiannual and annual sea levels near the eastern equatorial Indian Ocean boundary. J. Phys. Oceanogr., 23, 386-399.

Clarke, A. J., and X. Liu, 1994. Interannual sea level in the northern and eastern Indian Ocean, J. Phys. Oceanogr., 24, 1224-1235.

Gordon, A., S. Wijffels, J. Sprintall, D. Susanto, R. Molcard, H. V. Aken, A. Ffield,

I. Soesilo, and S. Wirasantosa, 2008. The Indonesian Throughflow, 3-year INSTANT composite view. CSIRO Marine and Atmospheric Research, unpublished manuscript.

Gordon, A. L., and R. D. Susanto, 2001. Banda Sea surface layer divergence. Ocean Dynamics, 52, 2-10.

Griffies, S. M., R. C. Pacanowski, and A. Rosati, 2004. A technical guide to MOM4, GFDL Ocean Group Technical Report No. 5. NOAA/Geophysical Fluid Dynamics Laboratory, 371 pp.

Hautala, S. L., J. Sprintall, J. Potemra, A. G. Ilahude, J. C. Chong, W. Pandoe, and N. Bray, 2001. Velocity structure and transport of the Indonesian Throughflow in the major straits restricting flow into the Indian Ocean. J. Geophys. Res., 106, 19,527-19,546.

Iskandar, I., W. Mardiansyah, Y. Masumoto, and T. Yamagata, 2005. Intraseasonal Kelvin waves along the southern coast of Sumatra and Java. J. Geophys. Res., 110, 10.1029/2004JC002,508.

Iskandar, I., T. Tozuka, H. Sasaki, Y. Masumoto, and T. Yamagata. 2006. Intraseasonal variations of surface and subsurface currents off Java as simulated in a high-resolution ocean general circulation 
model. J. Geophys. Res., 111, doi:10.1029/2006JC003,486.

Koch-Larrouy, A., G. Madec, P. Bouruet-Aubertot, T. Gerkema, L. Bessieres and R. Molcard. 2007. On the transformation of Pacific Water into Indonesian Throughflow Water by internal tidal mixing. Geophys. Res. Letters, 34, doi:10.1029/2006GL028405.

Large, W. G., and S. G. Yeager, 2004. Diurnal to decadal global forcing for ocean and sea-ice models: the data sets and flux climatologies. NCAR Technical Note, NCAR/TN-460+STR, 105p pp.

LeBlond, P. H., and L. A. Mysak, 1978. Waves in the ocean. 602 pp., Elsevier, Amsterdam, Elsevier Oceanography Series, 20.

McCreary, J. 1984. Equatorial Beams. J. Marine. Res., 42, 395-430.

Madden, R., and P. R. Julian, 1971. Detection of a 40-50 day oscillation in the zonal wind in the tropical Pacific. J. Atmos. Sc., 28, 802-708.

Murray, S. P., and D. Arief, 1988. Throughflow into the Indian Ocean through the Lombok Strait. January 1985-January 1986, Nature, 333, 444-447.

Oke, P. R., G. B. Brassington, D. A. Griffin, and A. Schiller, 2008. The Bluelink ocean data assimilation system (BODAS), Ocean Modelling. 21, doi:10.1016/j.ocemod.2007.11.002, 46-70.

Oke, P. R., G. B. Brassington, D. A. Griffin and A. Schiller, 2009. Data assimilation in the Australian Bluelink system. Mercator Newsletter, 34, 35-44.

Potemra, J. T., S. L. Hautala, J. Sprintall, and W. Pandoe, 2002. Interaction between the Indonesian Seas and the Indian Ocean in observation and numerical models. J. Phys. Oceanogr., 32, 1838-1854.

Qiu, B., M. Mao, and Y. Kashino, 1999. Intraseasonal variability in the Indo-Pacific Throughflow and the regions surrounding the Indonesian seas. J. Phys. Oceanogr., 29, 1599-1618.

Quadfasel, D., and G. Cresswell, 1992. A note on the seasonal variability of the South Java Current. J. Geophys. Res., 97, 3685-3688.

Schiller, A., and J. Godfrey, 2003. Indian Ocean intraseasonal variability in an ocean general circulation 
model. J. Climate, 16, 21-39.

Schiller, A., P. Oke, G. Brassington, M. Entel, R. Fiedler, D. Griffin, and J. Mans-bridge, 2008. Eddyresolving ocean circulation in the Asian-Australian region inferred from an ocean reanalysis effort. Progr. in Oceanogr., 76/3, 334-365, doi:10.1016/j.pocean.2008.01.003.

Schiller, A., K. Ridgway, C. R. Steinberg, and P. R. Oke, 2009. Dynamics of three anomalous SST events in the Coral Sea. Geophys. Res. Letters, 36, doi:10.1029/2008GL036,997.

Shinoda, T., H. H. Hendon, and J. Glick, 1998. Intraseasonal variability of surface fluxes and sea surface temperature in the tropical western Pacific and Indian Oceans. J. Clim., 11, $1685-1702$.

Sprintall, J., J. Chong, F. Syamsudin, W. Morawitz, N. Bray, and S. Wijffels, 1999. Dynamics of the south java current in the indo-australia basin. Geophys. Res. Letters, 26, 2493-2496.

Sprintall, J., A. L. Gordon, R. Murtugudde, and R. D. Susanto, 2000. A semiannual Indian Ocean forced Kelvin wave observed in the Indonesian seas in May 1997. J. Geophys. Res., 105, 17,217-17,230.

Sprintall, J., S. Wijffels, R. Molcard, and I. Jaya, 2009. Direct estimates of the Indonesian Throughflow entering the Indian Ocean: 2004-2006. J. Geophys. Res., p. submitted.

Syamsudin, F., A. Kaneko, and D. B. Haidvogel, 2004. Numerical and observational estimates of Indian Ocean Kelvin wave intrusion into Lombok Strait. Geophys. Res. Let., 31, 10.1029/2004GL021,227.

Wijffels, S. E., and G. Meyers, 2004. An intersection of oceanic waveguides -variability in the Indonesian Throughflow region. J. Phys. Oceanogr., 34, 1232-1253.

Wijffels, S. E., J. Sprintall, M. Fieux, and N. Bray, 2002. The JADE and WOCE I10/IR6 throughflow sections in the southeast Indian Ocean. Part I: water mass distribution and variability, Deep Sea Research, 49, 1341-1362.

Yu, Z., and J. Potemra (2006), Generation mechanism for the intraseasonal variability in the IndoAustralian basin, J. Geophys. Res., 111, doi:10.1029/2005JC003,023. 
Table 1: INSTANT Mooring Locations in Lombok, Ombai and Timor Straits

\begin{tabular}{|c|c|c|c|c|}
\hline Mooring & $\begin{array}{l}\text { Deployment } 1^{\mathrm{a}} \\
\text { Ranged in Position }\end{array}$ & $\begin{array}{l}\text { Deployment } 1^{\mathrm{a}} \\
\text { Depth }\end{array}$ & $\begin{array}{l}\text { Deployment } 2^{b} \\
\text { Ranged in Position }\end{array}$ & $\begin{array}{l}\text { Deployment } 2^{b} \\
\text { Depth }\end{array}$ \\
\hline Lombok West & $\begin{array}{l}115^{\circ} 45.6^{\prime} \mathrm{E} \\
8^{\circ} 26.4^{\prime} \mathrm{S}\end{array}$ & $921 \mathrm{~m}$ (est.) & $\begin{array}{l}115^{\circ} 45.5^{\prime} \mathrm{E} \\
8026.8^{\prime} \mathrm{S}\end{array}$ & $910 \mathrm{~m}$ \\
\hline Lombok East & $\begin{array}{l}115^{\circ} 53.9^{\prime} \mathrm{E} \\
8^{\circ} 24.1^{\prime} \mathrm{S}\end{array}$ & $1144 \mathrm{~m}$ & $\begin{array}{l}115^{\circ} 53.8^{\prime} \mathrm{E} \\
8^{\circ} 24.6^{\prime} \mathrm{S}\end{array}$ & $1133 \mathrm{~m}$ \\
\hline Ombai North & $\begin{array}{l}125^{\circ} 0.2^{\prime} \mathrm{E} \\
8^{\circ} 24.1^{\prime} \mathrm{S}\end{array}$ & $1329 \mathrm{~m}$ & $\begin{array}{l}125^{\circ} 2.3^{\prime} \mathrm{E} \\
8^{\circ} 24.0^{\prime} \mathrm{S}\end{array}$ & $1315 \mathrm{~m}$ \\
\hline Ombai South & $\begin{array}{l}12504.7^{\prime} \mathrm{E} \\
8^{\circ} 31.6^{\prime} \mathrm{S}\end{array}$ & $3224 \mathrm{~m}$ & $\begin{array}{l}125^{\circ} 32.3 . \mathrm{E} \\
8^{\circ} 32.3 . \mathrm{S}\end{array}$ & $3203 \mathrm{~m}$ \\
\hline Timor Roti & $\begin{array}{l}122^{\circ} 46.8^{\prime} \mathrm{E} \\
11^{\circ} 9.7^{\prime} \mathrm{S}\end{array}$ & $741 \mathrm{~m}$ & $\begin{array}{l}122^{\circ} 46.8^{\prime} \mathrm{E} \\
11^{\circ} 9.7^{\prime} \mathrm{S}\end{array}$ & $995 \mathrm{~m}$ \\
\hline Timor Sill & $\begin{array}{l}122^{\circ} 51.9^{\prime} \mathrm{E} \\
11^{\circ} 16.5^{\prime} \mathrm{S} \\
\text { (anchor drop) }\end{array}$ & 1890m (est.) & $\begin{array}{l}122^{\circ} 51.5^{\prime} \mathrm{E} \\
11^{\circ} 16.6^{\prime} \mathrm{S}\end{array}$ & $1874 \mathrm{~m}$ \\
\hline Timor South Slope & $\begin{array}{l}122^{\circ} 57.6^{\prime} \mathrm{E} \\
11^{\circ} 22.1^{\prime} \mathrm{S}\end{array}$ & $1386 \mathrm{~m}$ & $\begin{array}{l}122^{\circ} 57.4^{\prime} \mathrm{E} \\
11^{\circ} 22.2^{\prime} \mathrm{S}\end{array}$ & $1380 \mathrm{~m}$ \\
\hline Timor Ashmore & $\begin{array}{l}122^{\circ} 58.4^{\prime} \mathrm{E} \\
11^{\circ} 31.7^{\prime} \mathrm{S}\end{array}$ & $902 \mathrm{~m}$ & $\begin{array}{l}122^{\circ} 58.4^{\prime} \mathrm{E} \\
11^{\circ} 31.8^{\prime} \mathrm{S}\end{array}$ & $899 \mathrm{~m}$ \\
\hline
\end{tabular}

${ }^{a}$ Complete deployment of all moorings in phase 1: From January 2004 to July 2005

b Complete deployment of all moorings in phase 2: From July 2005 to December 2006 


\section{Figure Captions}

Figure 1: Bathymetry of Indonesian region (m). Lines denote location of ray paths (coloured lines) and black diamonds denote INSTANT moorings. Bifurcation point of path lines is at approximately $116^{\circ} \mathrm{E}, 9^{\mathrm{o}} \mathrm{S}$. Black box denotes area of Indian Ocean zonal wind stress anomalies and brown box denotes area of ITF wind stress anomalies. See text for further details.

Figure 2: Mean (solid lines) and standard deviation (dashed lines) of INSTANT (blue) and BRAN2.1 (red) along-strait velocity profiles for various mooring locations in Timor Sea (a-d), Ombai Strait (e, f) and Lombok Strait (g-h). Positive mean values denote eastward and northward directions.

Figure 3: Time-series of along-strait velocity anomalies versus depth (m) at moorings (a-b) Lombok East and (c-d) Ombai South, from (a,c) INSTANT and (b,d) BRAN2.1. Blue (red) denotes flow into (from) the Indian Ocean. Units are m/s.

Figure 4: Lagged correlation of 20-90 days bandpass-filtered zonal wind stress anomalies (Large and Yeager [2004]) for Indian Ocean box marked in Fig. 1 with bandpass-filtered sea-level anomalies (a-f) from altimetry (TOPEX Poseidon and ERS 1/2) and (g-1) from BRAN2.1 for lag increments of 7 days. Wind stress leads sea-level. The contour interval is 0.1 .

Figure 5: Correlation of potential temperature anomalies with equatorial Indian Ocean wind stress along ray path Sumatra-Java-Australia (red line in Fig. 1). Contour intervals are 0.2. Color scheme saturates at \pm 0.5 . Dashed lines and labels show positions marked in Fig. 6. Green line in (d) denotes ray path of equatorial Rossby wave and green line in (f) denotes ray path of Kelvin wave.

Figure 6: Composites of potential temperature anomalies at depth of $z=145 \mathrm{~m}$ for (a-g) negative and (h-n) positive intraseasonal events. Day 0: peak of negative and positive wind stress anomalies in 
equatorial box shown in Fig. 1. The colour schemes saturates at $(\mathrm{a}-\mathrm{g}) \pm 1.5{ }^{\circ} \mathrm{C}$ and $(\mathrm{h}-\mathrm{n}) \pm 2.0^{\circ} \mathrm{C}$.

Figure 7: Composites of potential temperature anomalies along ray path Sumatra-Java-Australia (red line in Fig. 1) for positive intraseasonal event. Day 0: peak of positive wind stress anomalies in equatorial box shown in Fig. 1. The colour scheme saturates at $\pm 0.5^{\circ}$ C. C.I.: $0.2^{\circ}$ C. Dashed lines and labels denote positions marked in Fig. 1.

Figure 8: Composites of along-track velocity anomalies along ray path Lombok-Makassar Strait (green line in Fig. 1) for positive intraseasonal event. Day 0: peak of positive wind stress anomalies in equatorial box shown in Fig. 1 . The colour scheme saturates at $\pm 0.1 \mathrm{~m} / \mathrm{s}$. C.I.: $0.02 \mathrm{~m} / \mathrm{s}$. Dashed lines and labels denote positions marked in Fig. 1.

Figure 9: Composites of potential temperature anomalies along ray path Lombok-Savu Sea-Ombai Strait -Banda Sea (blue line in Fig. 1) for positive intraseasonal event. Day 0: peak of positive wind stress anomalies in equatorial box shown in Fig. 1 . The colour scheme saturates at $\pm 0.5{ }^{\circ}$ C. C.I.: $0.2^{\circ} \mathrm{C}$. Dashed line and label denote position marked in Fig. 1.

Figure 10: Composites of along-track velocity anomalies along ray path Lombok-Savu Sea-Ombai Strait-Banda Sea (blue line in Fig. 1) for positive intraseasonal event. Day 0: peak of positive wind stress anomalies in equatorial box shown in Fig. 1 . The colour scheme saturates at $\pm 0.1 \mathrm{~m} / \mathrm{s}$. C.I.: 0.02 $\mathrm{m} / \mathrm{s}$. Dashed line and label denote position marked in Fig. 1.

Figure 11: Composites of potential temperature anomalies along ray path Timor Strait-Banda Sea (yellow line in Fig. 1) for positive intraseasonal event. Day 0: peak of positive wind stress anomalies in equatorial box shown in Fig. 1. The colour scheme saturates at $\pm 0.5{ }^{\circ}$ C. C.I.: $0.2{ }^{\circ}$ C. Dashed line and label denote position marked in Fig. 1. 
Figure 12: Time-depth plots of composites of potential temperature anomalies at mooring Lombok East for $(a, c)$ BRAN2.1 and (b, d) observations. Day 0: peak of negative and positive wind stress anomalies in equatorial box shown in Fig. 1. The colour scheme saturates at $\pm 1.0^{\circ}$ C. C.I.: $0.1{ }^{\circ}$ C. Note missing near-surface data in observations.

Figure 13: Time-depth plots of composites of along-track velocity anomalies at mooring Lombok East for $(a, c)$ BRAN2.1 and $(b, d)$ observations. Day 0: peak of negative and positive wind stress anomalies in equatorial box shown in Fig. 1 . The colour scheme saturates at $\pm 1.0 \mathrm{~m} / \mathrm{s}$. C.I.: $0.1 \mathrm{~m} / \mathrm{s}$.

Figure 14: Time-depth plots of composites of potential temperature anomalies at mooring Ombai South for $(a, c)$ BRAN2.1 and $(b, d)$ observations. Day 0: peak of negative and positive wind stress anomalies in equatorial box shown in Fig. 1. The colour scheme saturates at $\pm 0.5^{\circ}$ C. C.I.: $0.1{ }^{\circ}$ C. Note missing near-surface data in observations.

Figure 15: Time-depth plots of composites of along-track velocity anomalies at mooring Ombai South for $(\mathrm{a}, \mathrm{c})$ BRAN2.1 and $(\mathrm{b}, \mathrm{d})$ observations. Day 0: peak of negative and positive wind stress anomalies in equatorial box shown in Fig. 1 . The colour scheme saturates at $\pm 0.5 \mathrm{~m} / \mathrm{s}$. C.I.: $0.1 \mathrm{~m} / \mathrm{s}$.

Figure 16: Time-depth plots of composites of potential temperature anomalies at mooring Timor Roti for $(a, c)$ BRAN2.1 and $(b, d)$ observations. Day 0: peak of negative and positive wind stress anomalies in equatorial box shown in Fig. 1. The colour scheme saturates at $\pm 0.5{ }^{\circ}$ C. C.I.: $0.1{ }^{\circ}$ C. Note missing near-surface data in observations.

Figure 17: Time-depth plots of composites of along-track velocity anomalies at mooring Timor Roti for $(a, c)$ BRAN2.1 and $(b, d)$ observations. Day 0: peak of negative and positive wind stress anomalies in equatorial box shown in Fig. 1. The colour scheme saturates at $\pm 0.2 \mathrm{~m} / \mathrm{s}$. C.I.: $0.1 \mathrm{~m} / \mathrm{s}$. 
Figure 18: Composites of (a-g) zonal and (h-n) meridional velocity anomalies at depth of $\mathrm{z}=5 \mathrm{~m}$ for positive intraseasonal event. Day 0: peak of positive wind stress anomalies in ITF box marked in Fig. 1. The colour scheme saturates at $\pm 0.5 \mathrm{~m} / \mathrm{s}$.

Figure 19: Time-depth plots of composites of potential temperature anomalies at mooring Ombai South for $(a, c)$ BRAN2.1 and $(b, d)$ observations. Day 0: peak of negative and positive wind stress anomalies in ITF box shown in Fig. 1. The colour scheme saturates at $\pm 0.5^{\circ}$ C. C.I.: $0.1{ }^{\circ} \mathrm{C}$. Note missing near-surface data in observations.

Figure 20: Time-depth plots of composites of potential temperature anomalies at mooring Timor Roti for $(a, c)$ BRAN2.1 and $(b, d)$ observations. Day 0: peak of negative and positive wind stress anomalies in ITF box shown in Fig. 1 . The colour scheme saturates at $\pm 0.5{ }^{\circ}$ C. C.I.: $0.1{ }^{\circ}$ C. Note missing nearsurface data in observations. 


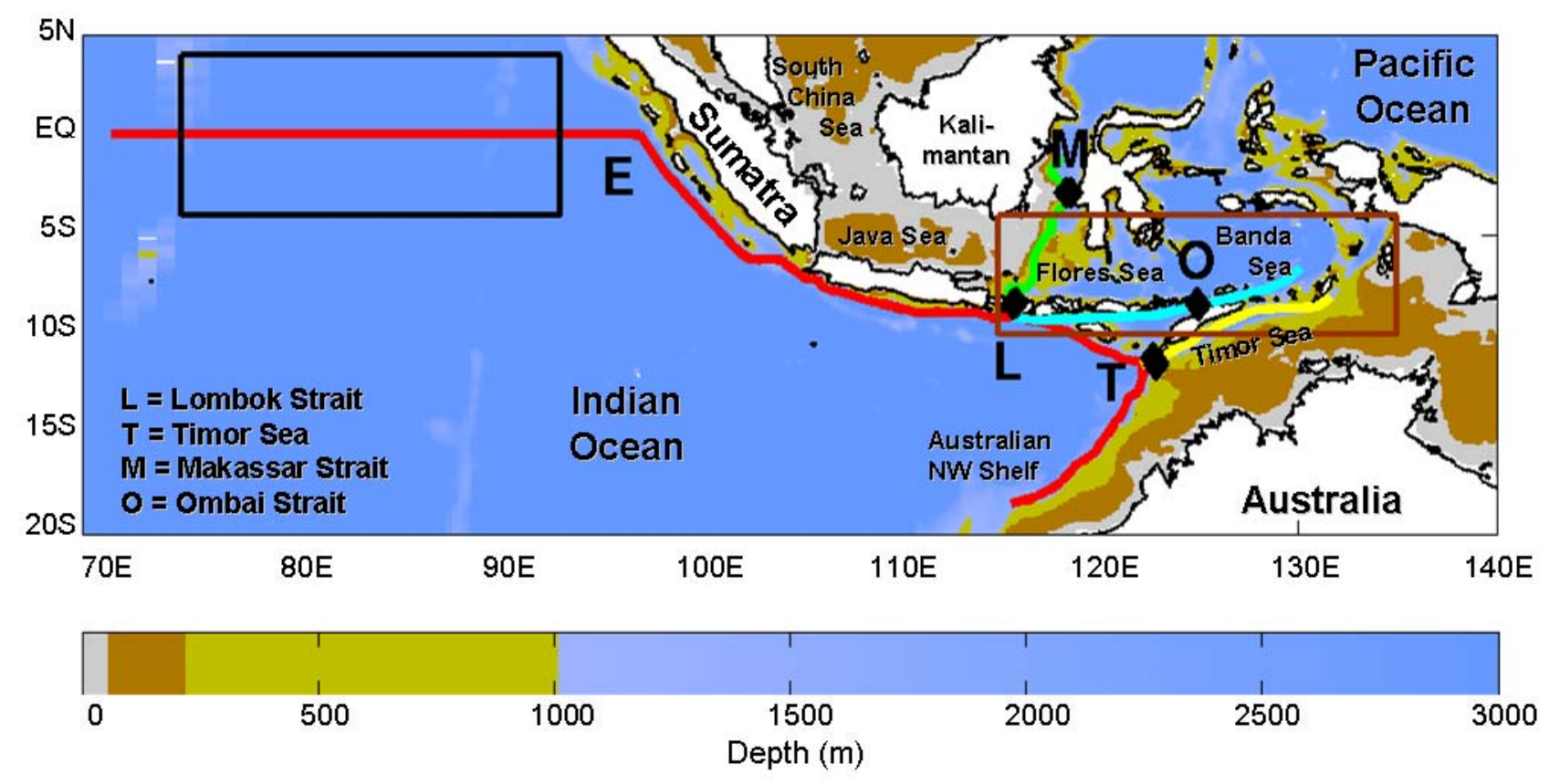

Figure 1: Bathymetry of Indonesian region (m). Lines denote location of ray paths (coloured lines) and black diamonds denote INSTANT moorings. Bifurcation point of path lines is at approximately $116^{\circ} \mathrm{E}, 9^{\circ} \mathrm{S}$. Black box denotes area of Indian Ocean zonal wind stress anomalies and brown box denotes area of ITF wind stress anomalies. See text for further details. 

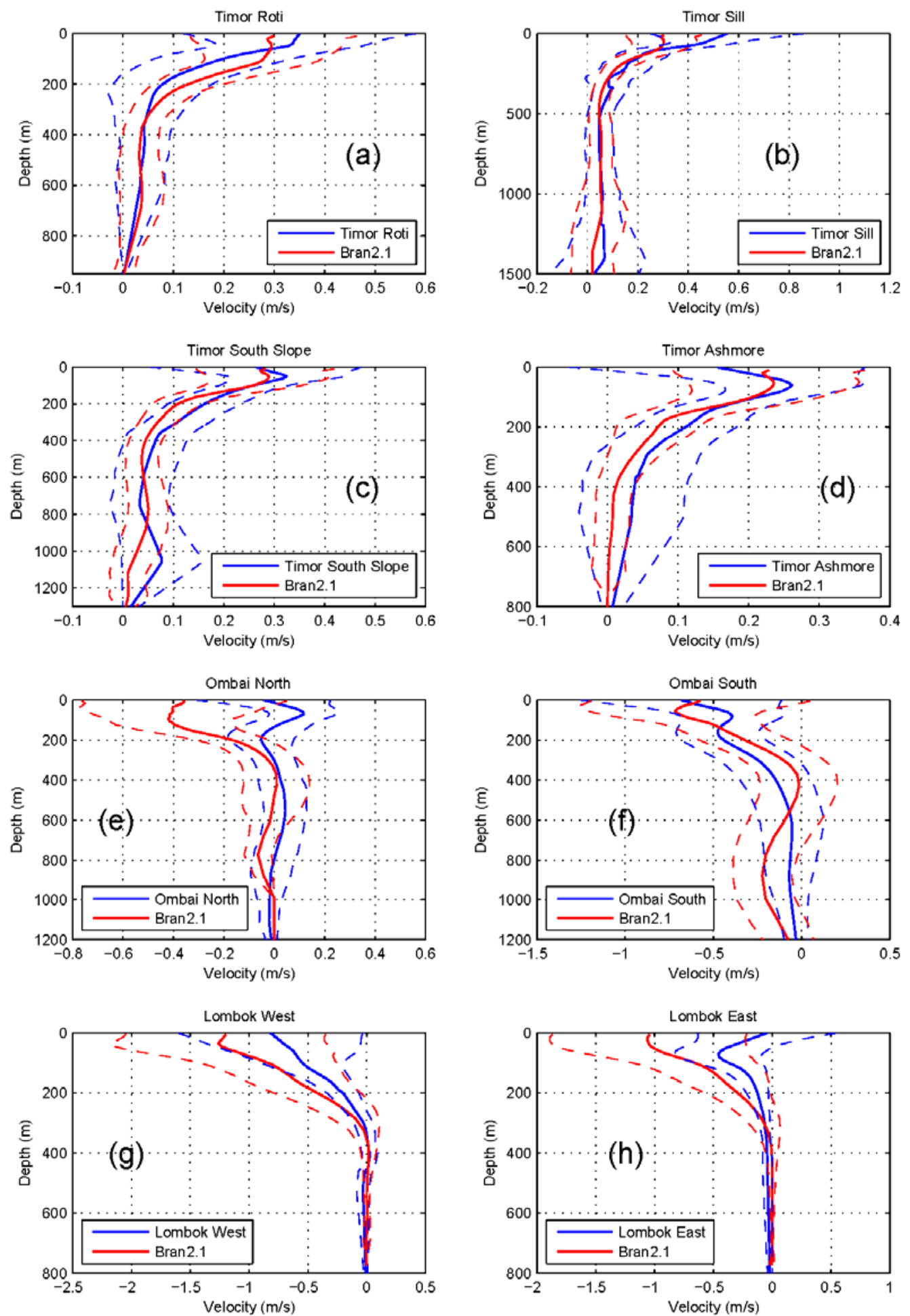

Figure 2: Mean (solid lines) and standard deviation (dashed lines) of INSTANT (blue) and BRAN2.1 (red) along-strait velocity profiles for various mooring locations in Timor Sea (a-d), Ombai Strait (e, f) and Lombok Strait (g-h). Positive mean values denote eastward and northward directions. 

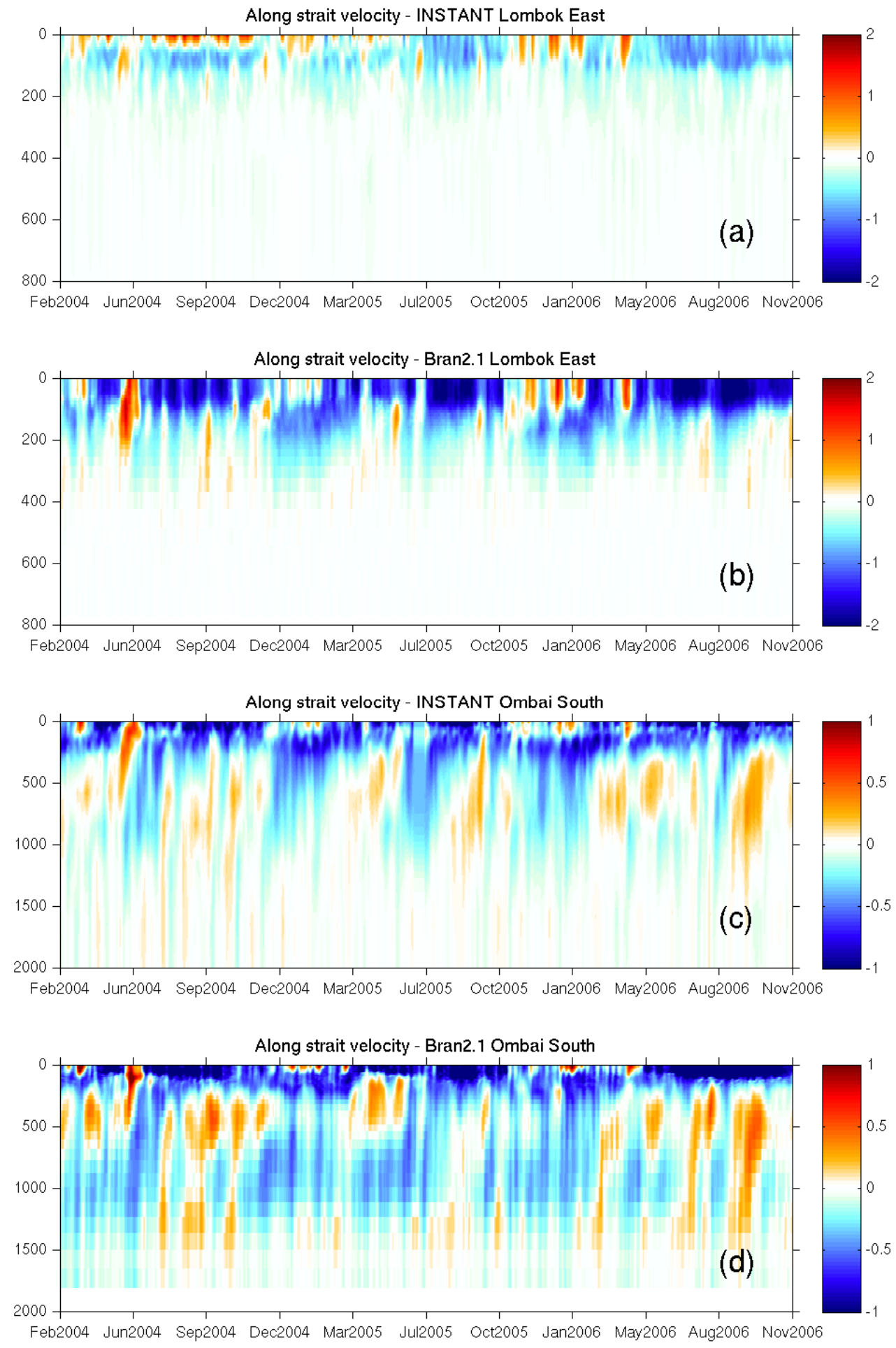

Figure 3: Time-series of along-strait velocity anomalies versus depth (m) at moorings (a-b) Lombok East and (c-d) Ombai South, from (a,c) INSTANT and (b,d) BRAN2.1. Blue (red) denotes flow into (from) the Indian Ocean. Units are m/s. 


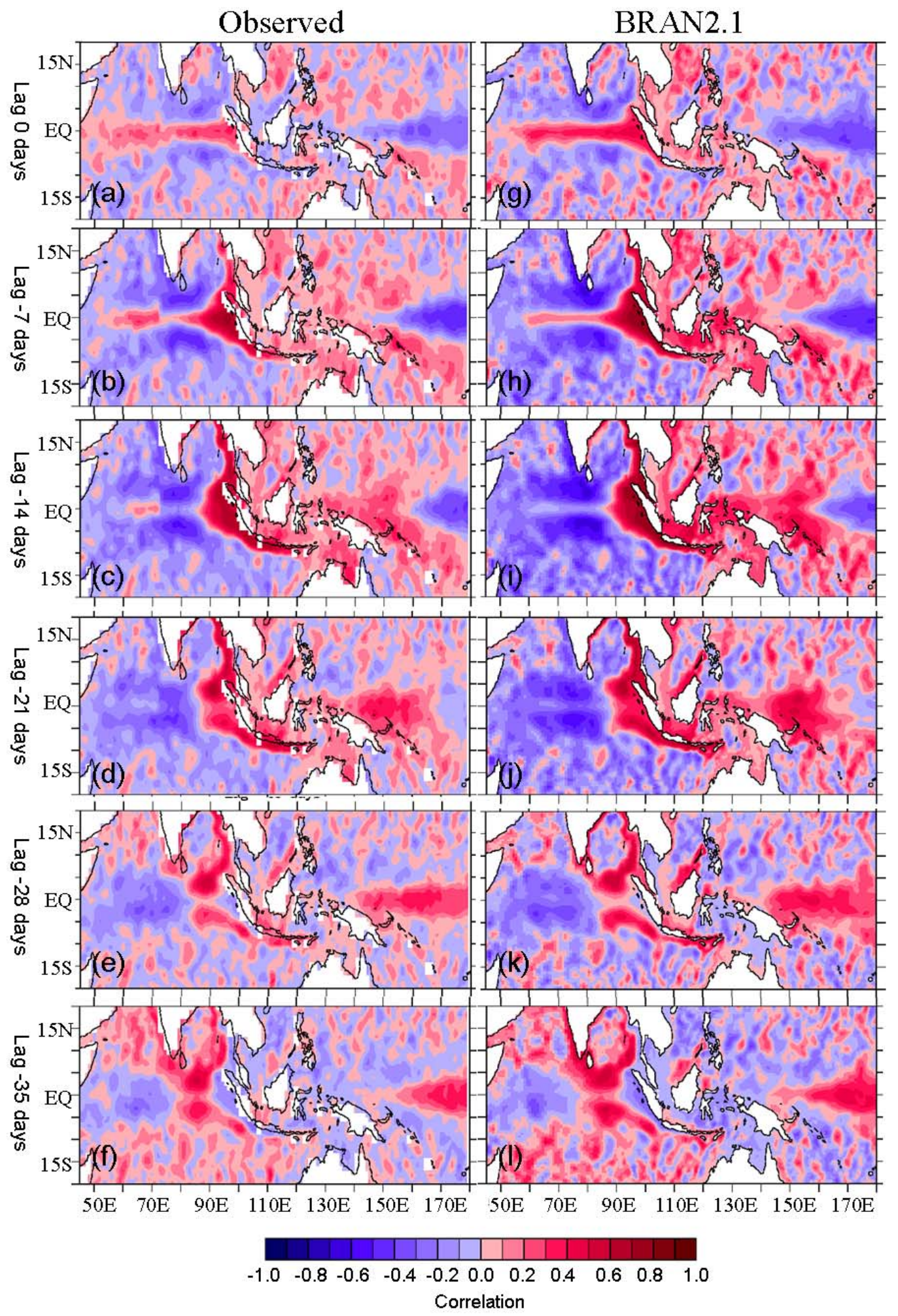

Figure 4: Lagged correlation of 20-90 days bandpass-filtered zonal wind stress anomalies (Large and Yeager [2004]) for Indian Ocean box marked in Fig. 1 with bandpass-filtered sea-level anomalies (a-f) from altimetry (TOPEX Poseidon and ERS 1/2) and (g-1) from BRAN2.1 for lag increments of 7 days. Wind stress leads sea-level. The contour interval is 0.1 . 

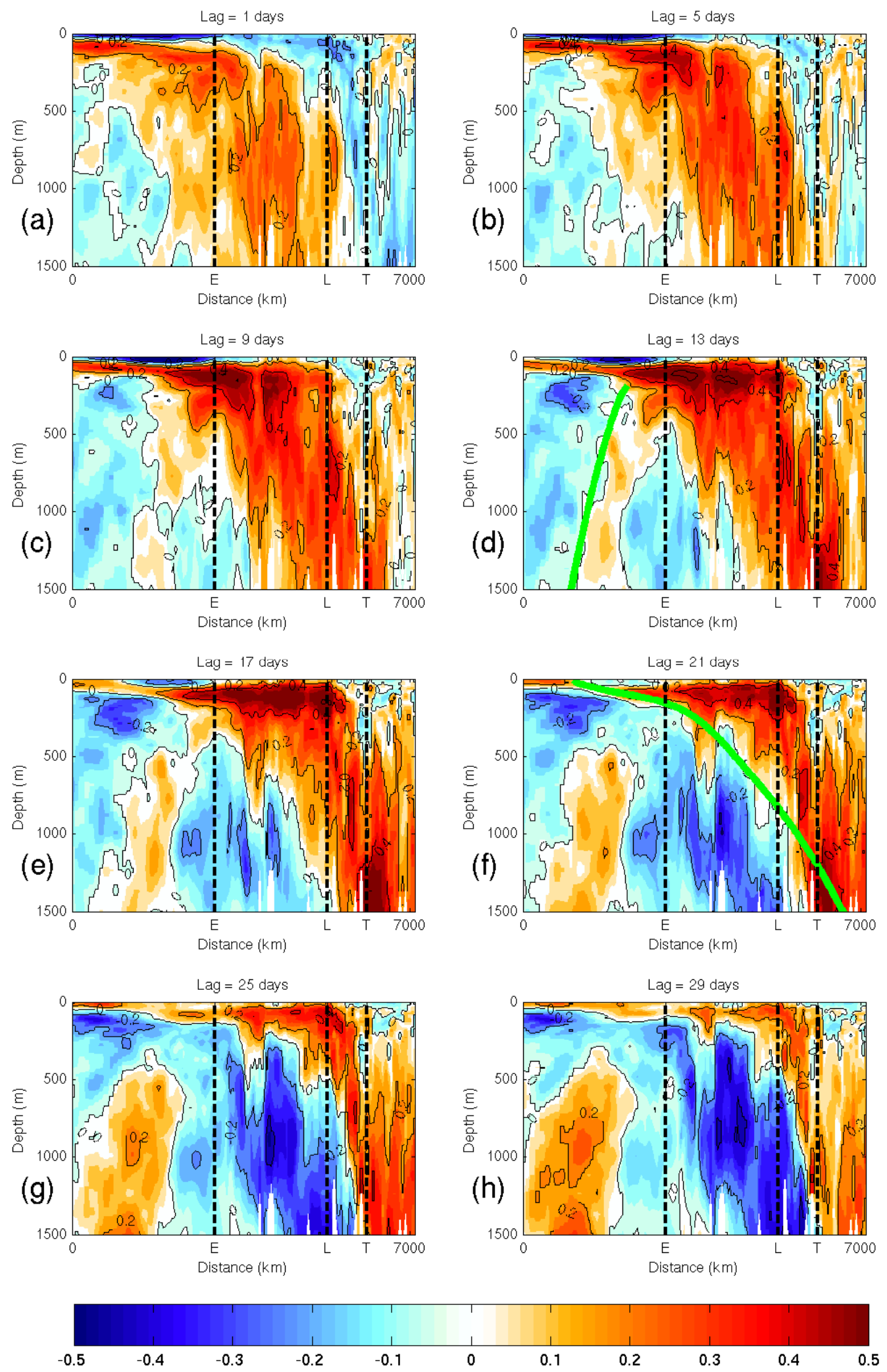

Figure 5: Correlation of potential temperature anomalies with equatorial Indian Ocean wind stress along ray path Sumatra-Java-Australia (red line in Fig. 1). Contour intervals are 0.2. Color scheme saturates at \pm 0.5 . Dashed lines and labels show positions marked in Fig. 6. Green line in (d) denotes ray path of equatorial Rossby wave and green line in (f) denotes ray path of Kelvin wave. 


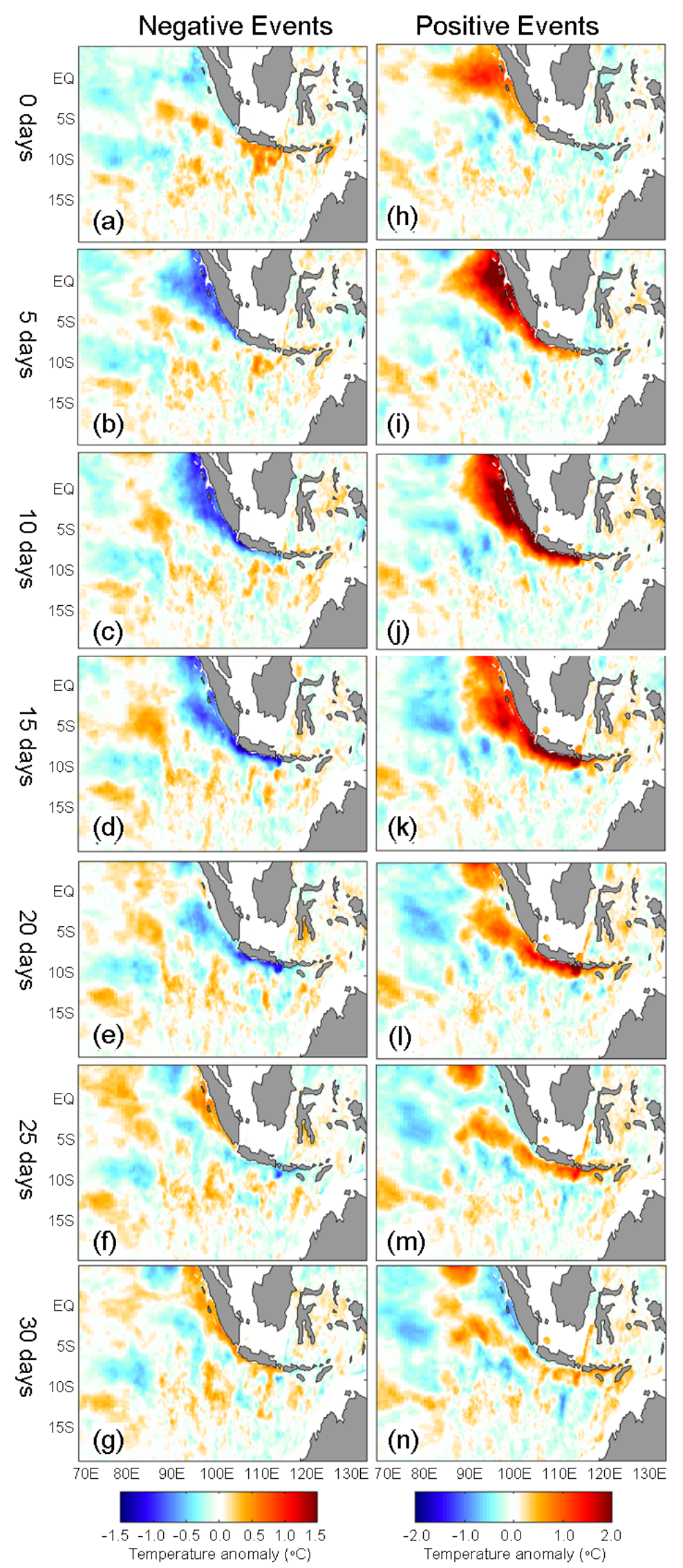

Figure 6: Composites of potential temperature anomalies at depth of $z=145 \mathrm{~m}$ for (a-g) negative and (h-n) positive intraseasonal events. Day 0: peak of negative and positive wind stress anomalies in equatorial box shown in Fig. 1. The colour schemes saturates at $(\mathrm{a}-\mathrm{g}) \pm 1.5{ }^{\circ} \mathrm{C}$ and $(\mathrm{h}-\mathrm{n}) \pm 2.0^{\circ} \mathrm{C}$. 

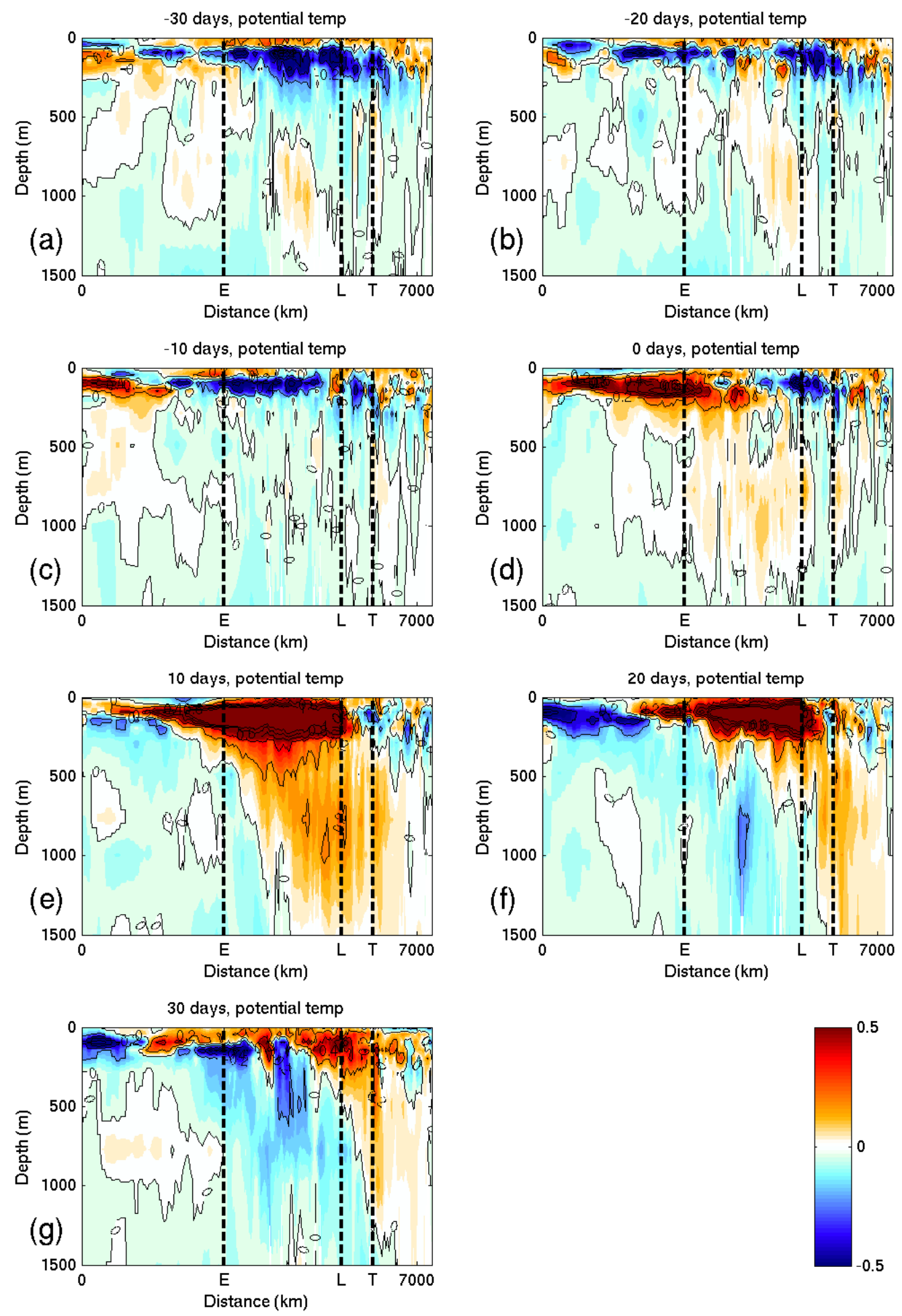

Figure 7: Composites of potential temperature anomalies along ray path Sumatra-Java-Australia (red line in Fig. 1) for positive intraseasonal event. Day 0: peak of positive wind stress anomalies in equatorial box shown in Fig. 1. The colour scheme saturates at $\pm 0.5^{\circ}$ C. C.I.: $0.2^{\circ}$ C. Dashed lines and labels denote positions marked in Fig. 1. 

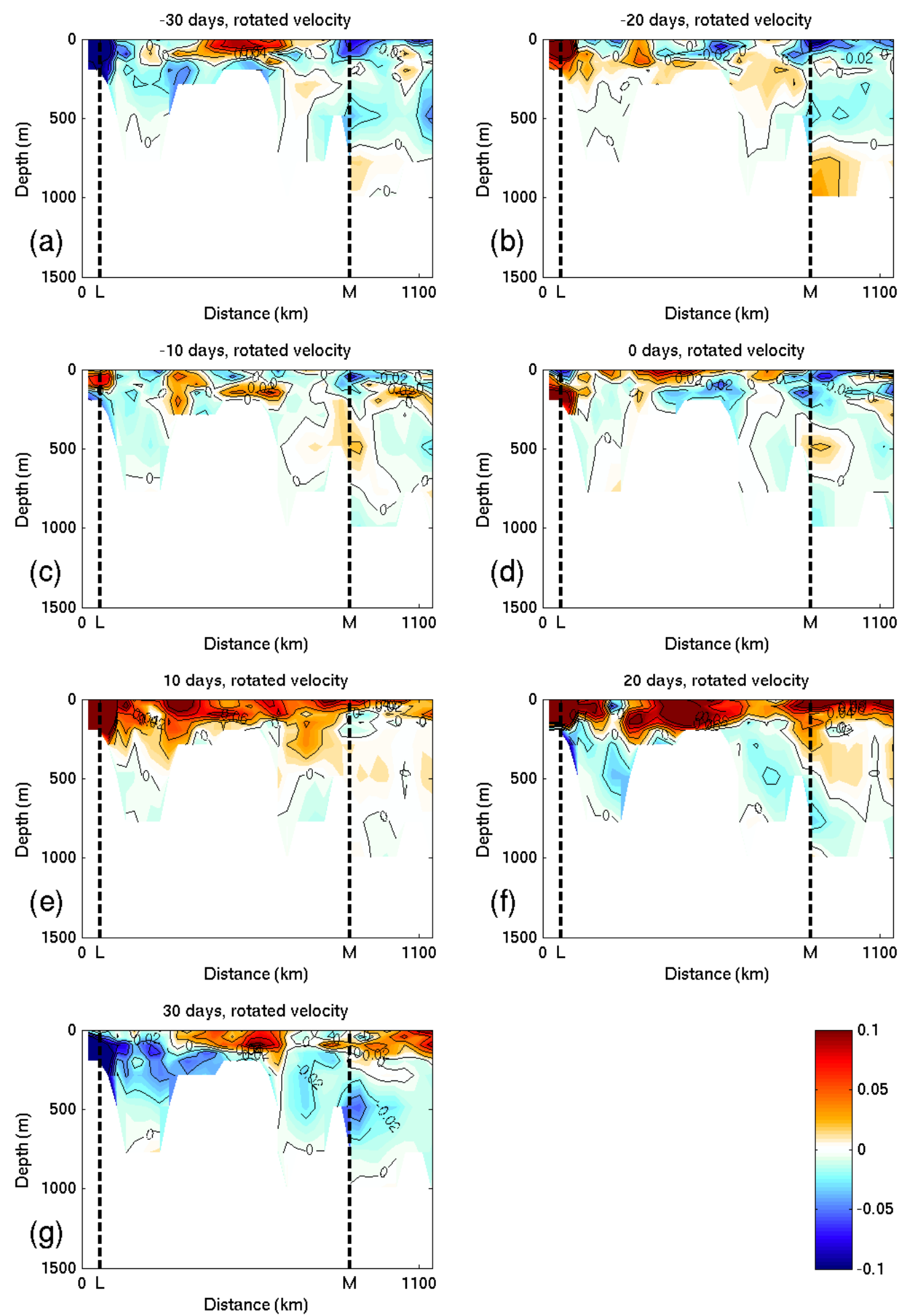

Figure 8: Composites of along-track velocity anomalies along ray path Lombok-Makassar Strait (green line in Fig. 1) for positive intraseasonal event. Day 0: peak of positive wind stress anomalies in equatorial box shown in Fig. 1 . The colour scheme saturates at $\pm 0.1 \mathrm{~m} / \mathrm{s}$. C.I.: $0.02 \mathrm{~m} / \mathrm{s}$. Dashed lines and labels denote positions marked in Fig. 1. 

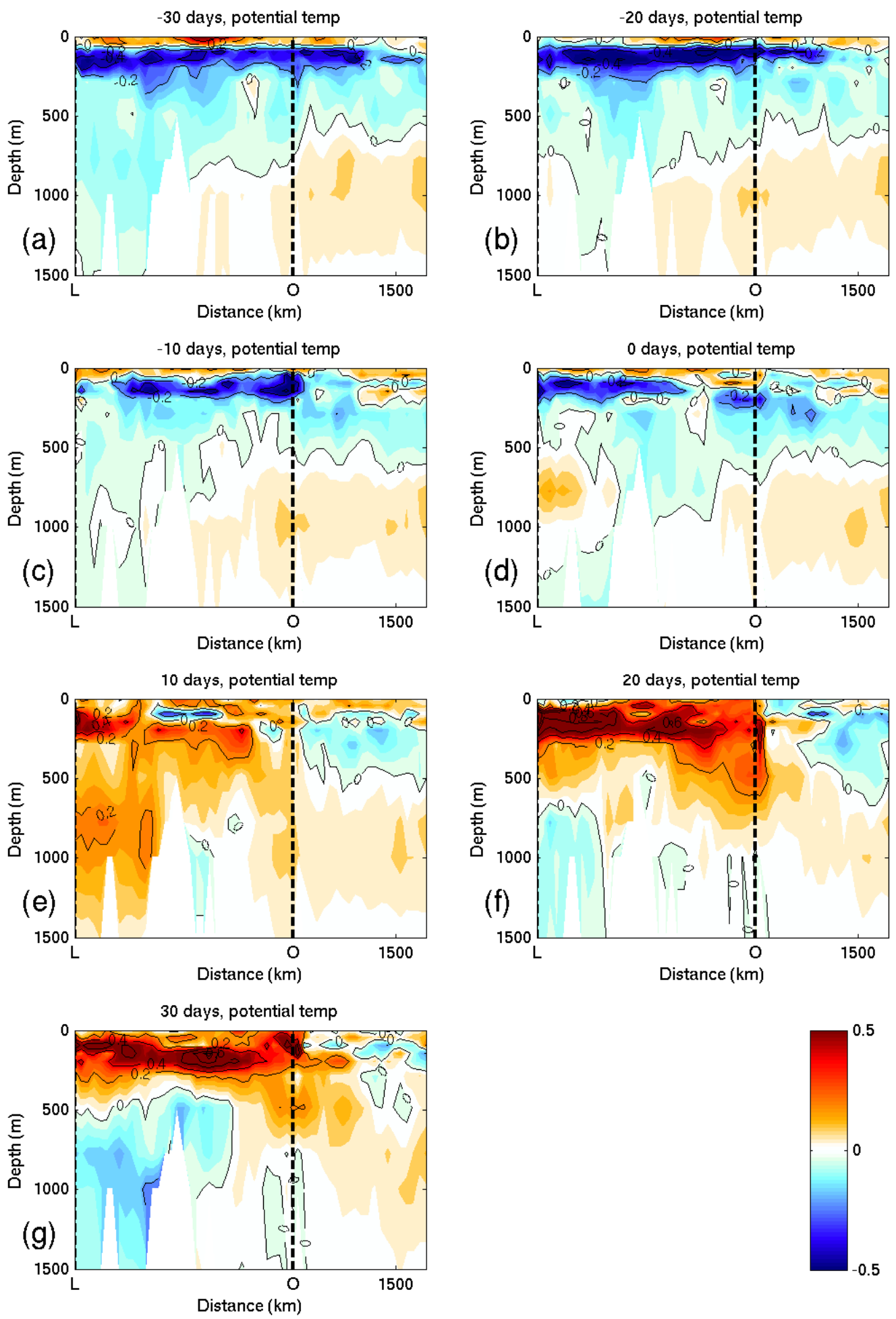

Figure 9: Composites of potential temperature anomalies along ray path Lombok-Savu Sea-Ombai Strait -Banda Sea (blue line in Fig. 1) for positive intraseasonal event. Day 0: peak of positive wind stress anomalies in equatorial box shown in Fig. 1 . The colour scheme saturates at $\pm 0.5^{\circ}$ C. C.I.: $0.2^{\circ}$ C. Dashed line and label denote position marked in Fig. 1. 

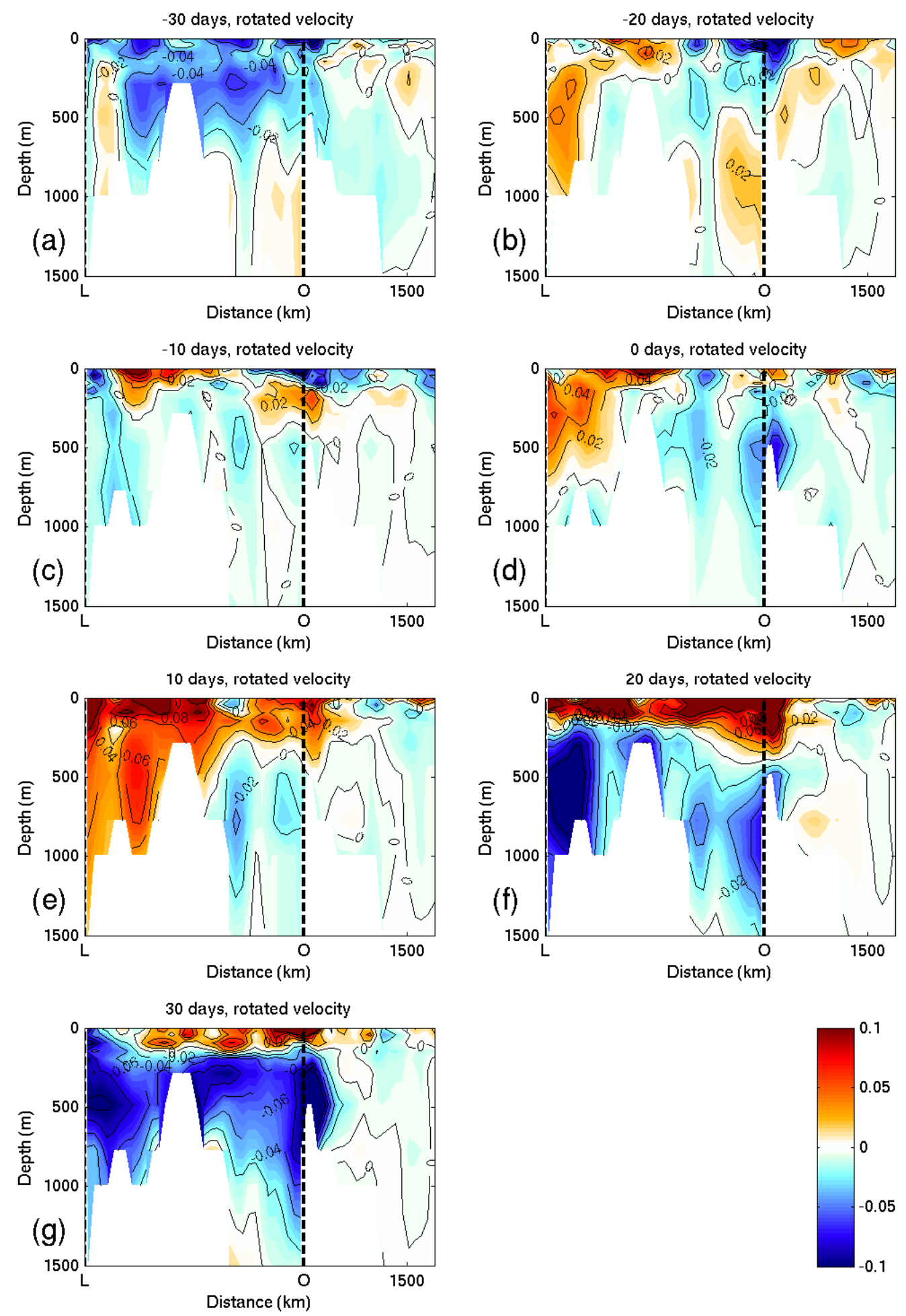

Figure 10: Composites of along-track velocity anomalies along ray path Lombok-Savu Sea-Ombai Strait-Banda Sea (blue line in Fig. 1) for positive intraseasonal event. Day 0: peak of positive wind stress anomalies in equatorial box shown in Fig. 1 . The colour scheme saturates at $\pm 0.1 \mathrm{~m} /$ s. C.I.: 0.02 $\mathrm{m} / \mathrm{s}$. Dashed line and label denote position marked in Fig. 1. 

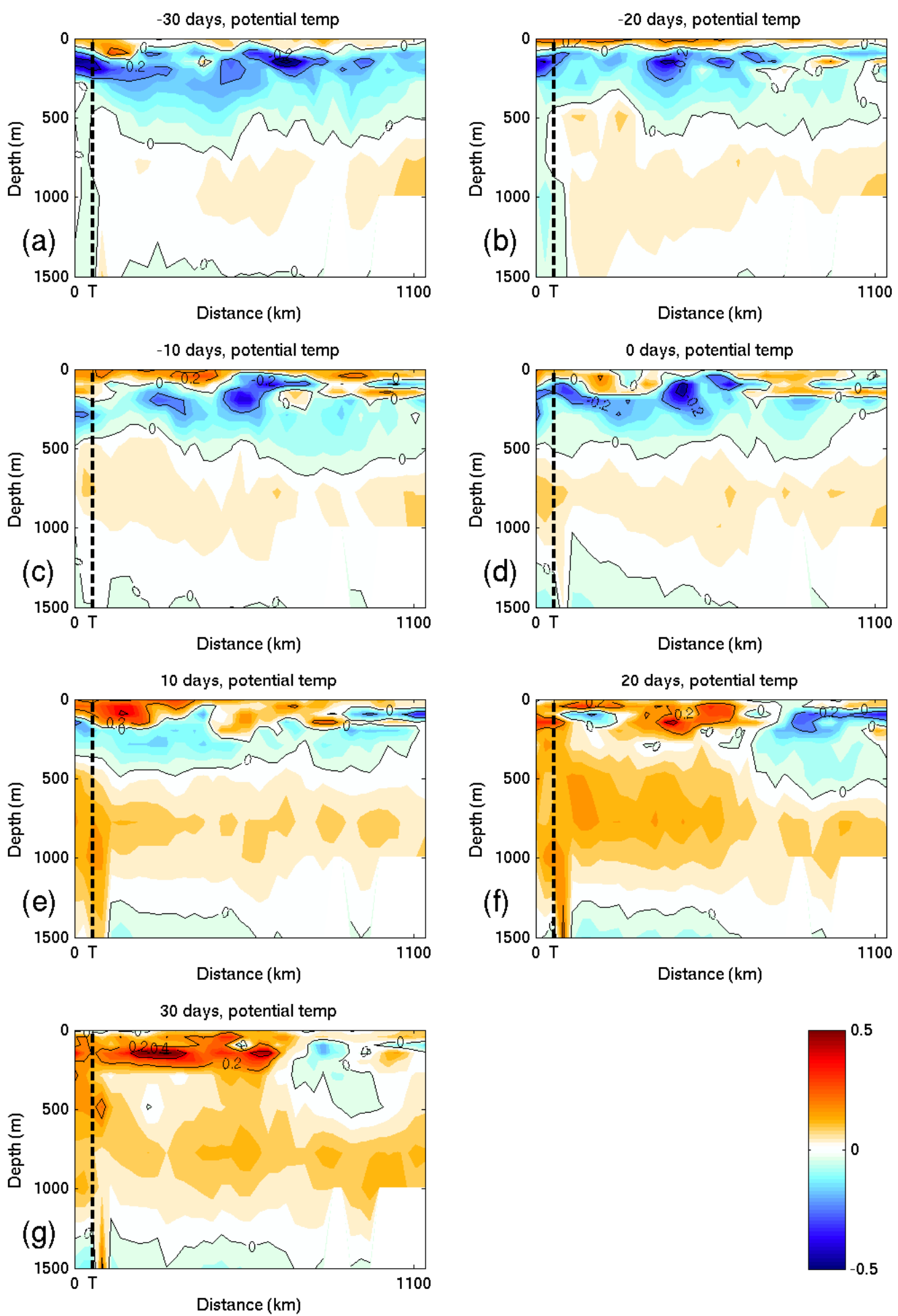

Figure 11: Composites of potential temperature anomalies along ray path Timor Strait-Banda Sea (yellow line in Fig. 1) for positive intraseasonal event. Day 0: peak of positive wind stress anomalies in equatorial box shown in Fig. 1 . The colour scheme saturates at $\pm 0.5{ }^{\circ}$ C. C.I.: $0.2{ }^{\circ}$ C. Dashed line and label denote position marked in Fig. 1. 

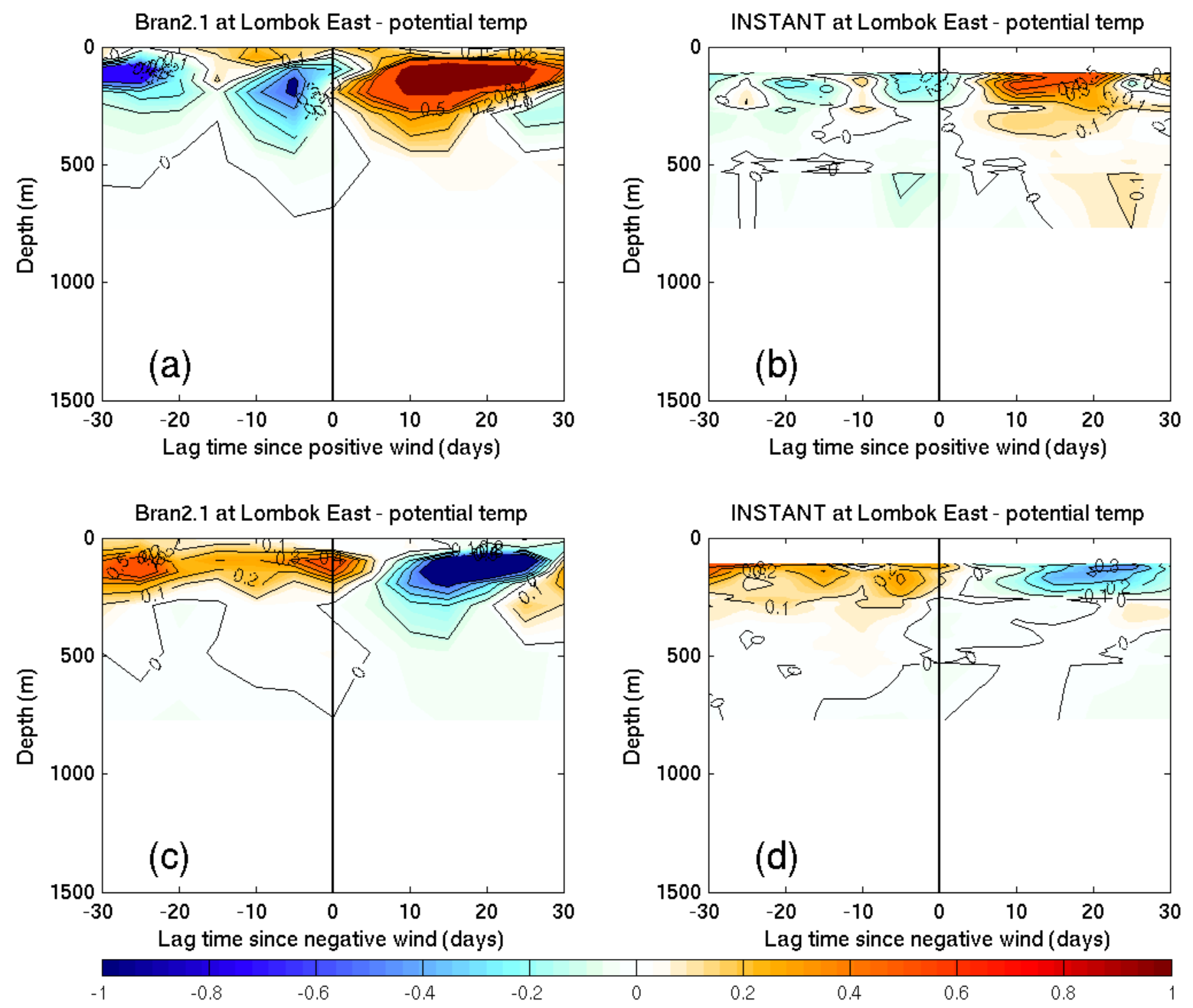

Figure 12: Time-depth plots of composites of potential temperature anomalies at mooring Lombok East for $(a, c)$ BRAN2.1 and $(b, d)$ observations. Day 0: peak of negative and positive wind stress anomalies in equatorial box shown in Fig. 1. The colour scheme saturates at $\pm 1.0^{\circ}$ C. C.I.: $0.1{ }^{\circ}$ C. Note missing near-surface data in observations. 

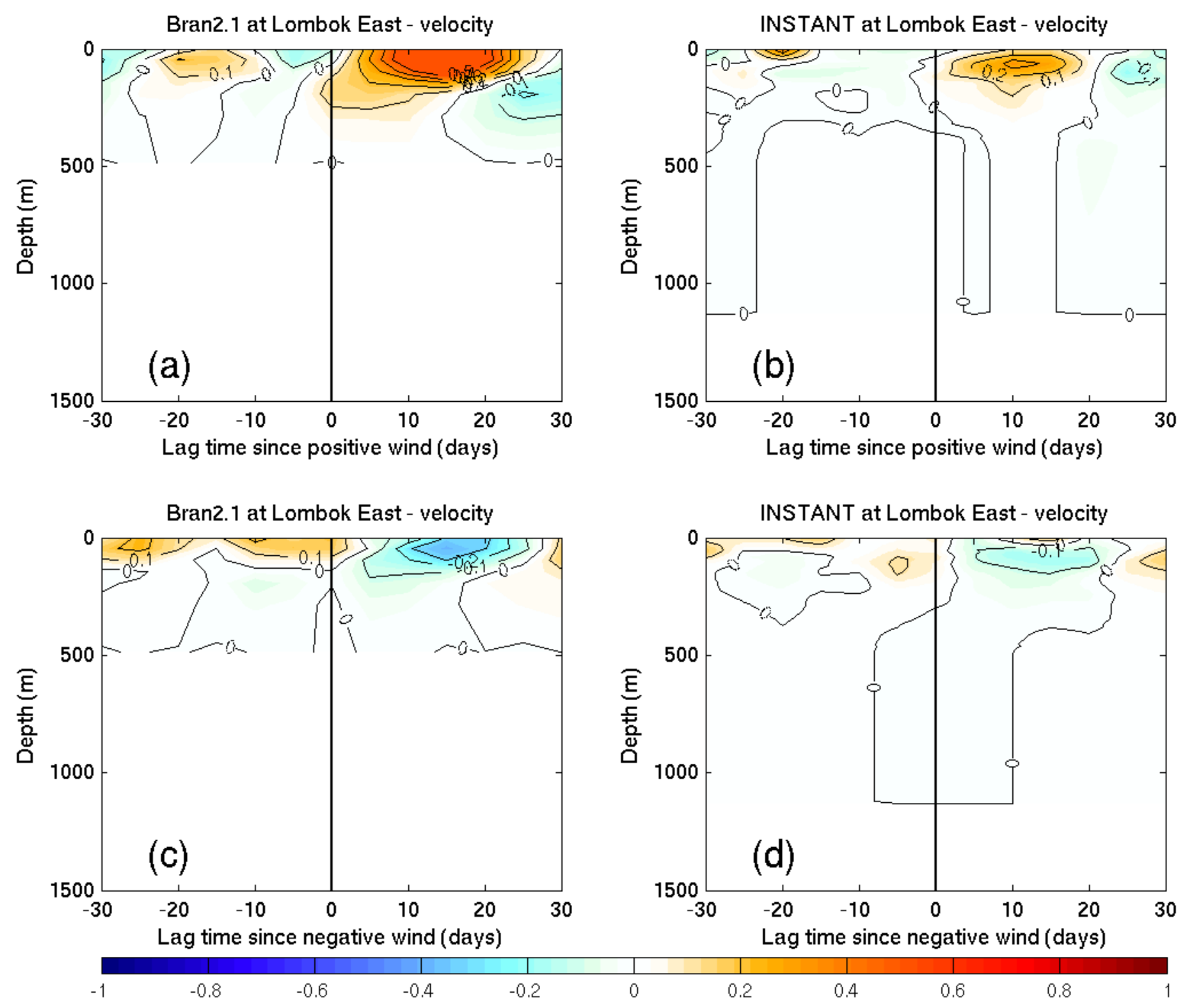

Figure 13: Time-depth plots of composites of along-track velocity anomalies at mooring Lombok East for $(a, c)$ BRAN2.1 and $(b, d)$ observations. Day 0: peak of negative and positive wind stress anomalies in equatorial box shown in Fig. 1 . The colour scheme saturates at $\pm 1.0 \mathrm{~m} / \mathrm{s}$. C.I.: $0.1 \mathrm{~m} / \mathrm{s}$. 

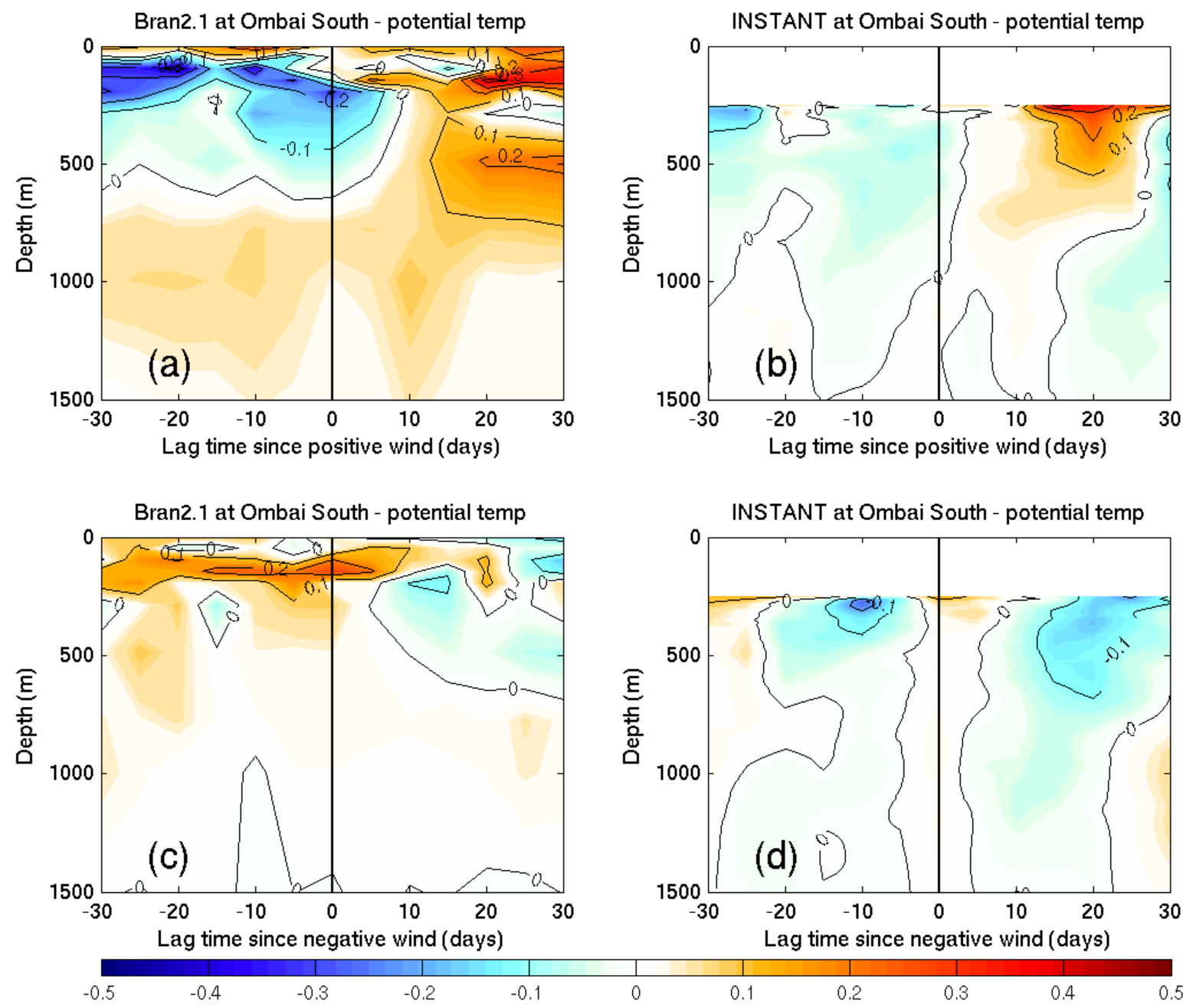

Figure 14: Time-depth plots of composites of potential temperature anomalies at mooring Ombai South for $(a, c)$ BRAN2.1 and $(b, d)$ observations. Day 0: peak of negative and positive wind stress anomalies in equatorial box shown in Fig. 1 . The colour scheme saturates at $\pm 0.5{ }^{\circ}$ C. C.I.: $0.1{ }^{\circ}$ C. Note missing near-surface data in observations. 

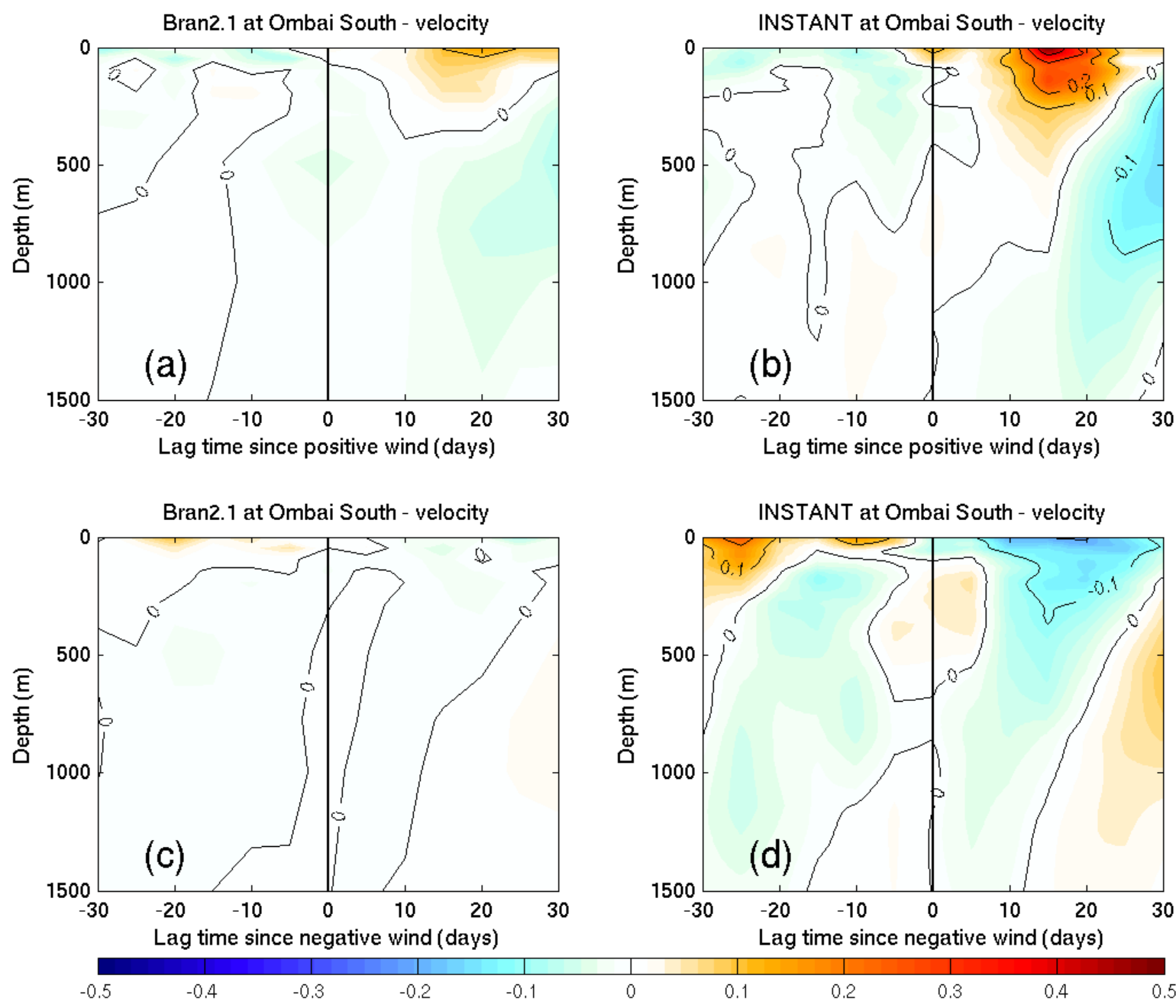

Figure 15: Time-depth plots of composites of along-track velocity anomalies at mooring Ombai South for $(a, c)$ BRAN2.1 and $(b, d)$ observations. Day 0: peak of negative and positive wind stress anomalies in equatorial box shown in Fig. 1 . The colour scheme saturates at $\pm 0.5 \mathrm{~m} / \mathrm{s}$. C.I.: $0.1 \mathrm{~m} / \mathrm{s}$. 

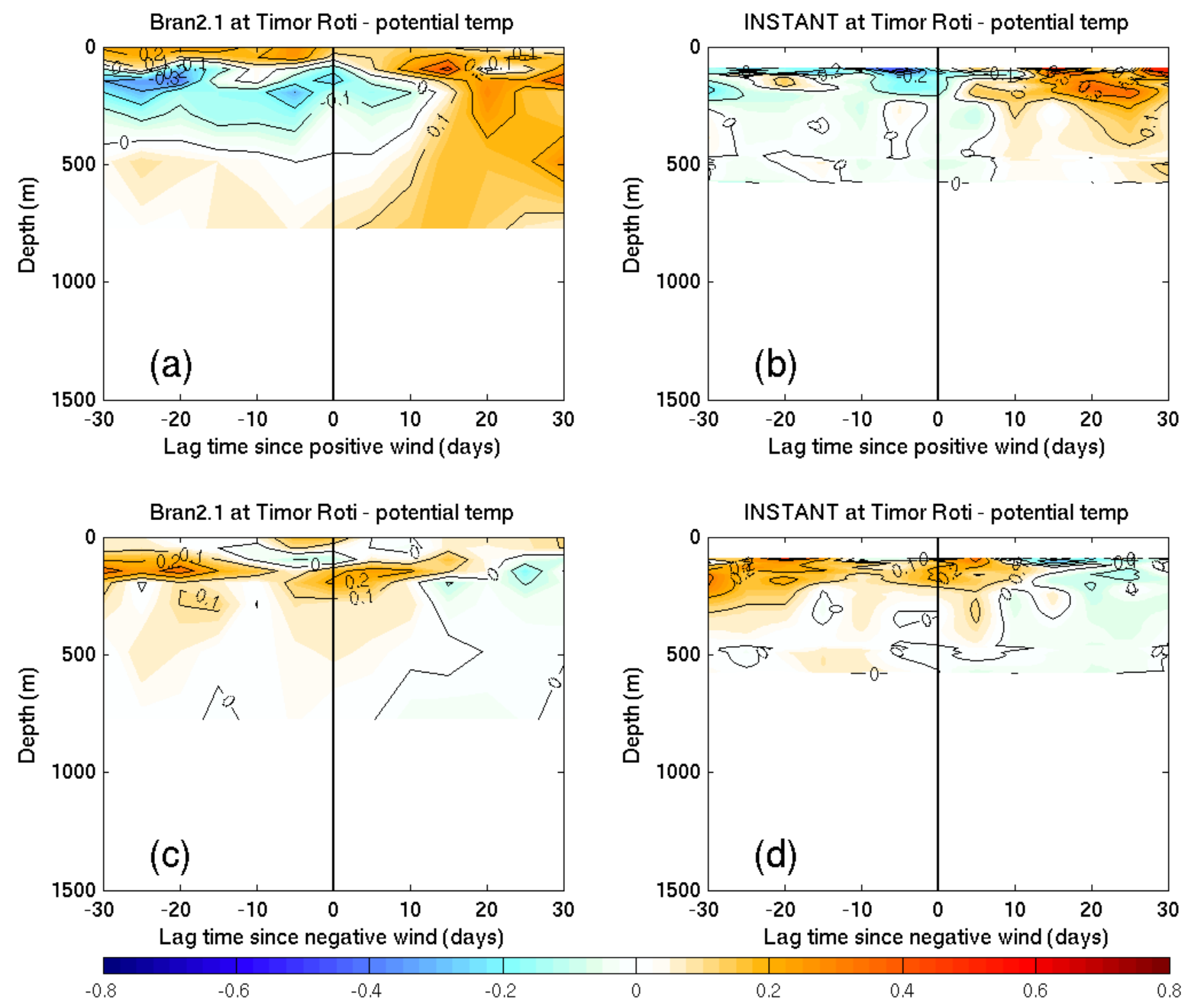

Figure 16: Time-depth plots of composites of potential temperature anomalies at mooring Timor Roti for $(\mathrm{a}, \mathrm{c})$ BRAN2.1 and $(\mathrm{b}, \mathrm{d})$ observations. Day 0: peak of negative and positive wind stress anomalies in equatorial box shown in Fig. 1. The colour scheme saturates at $\pm 0.5{ }^{\circ}$ C. C.I.: $0.1{ }^{\circ}$ C. Note missing near-surface data in observations. 

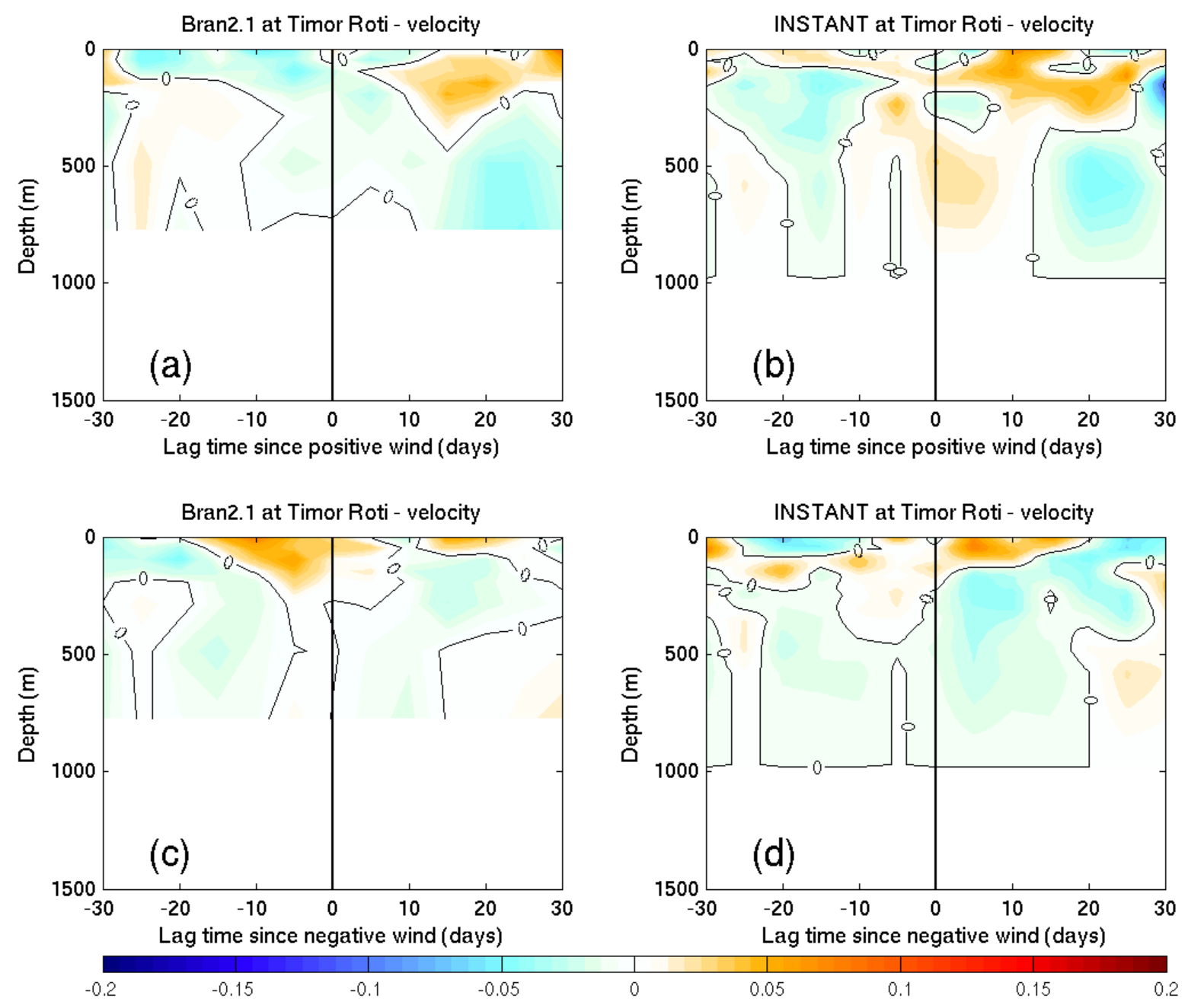

Figure 17: Time-depth plots of composites of along-track velocity anomalies at mooring Timor Roti for $(a, c)$ BRAN2.1 and $(b, d)$ observations. Day 0: peak of negative and positive wind stress anomalies in equatorial box shown in Fig. 1 . The colour scheme saturates at $\pm 0.2 \mathrm{~m} / \mathrm{s}$. C.I.: $0.1 \mathrm{~m} / \mathrm{s}$. 


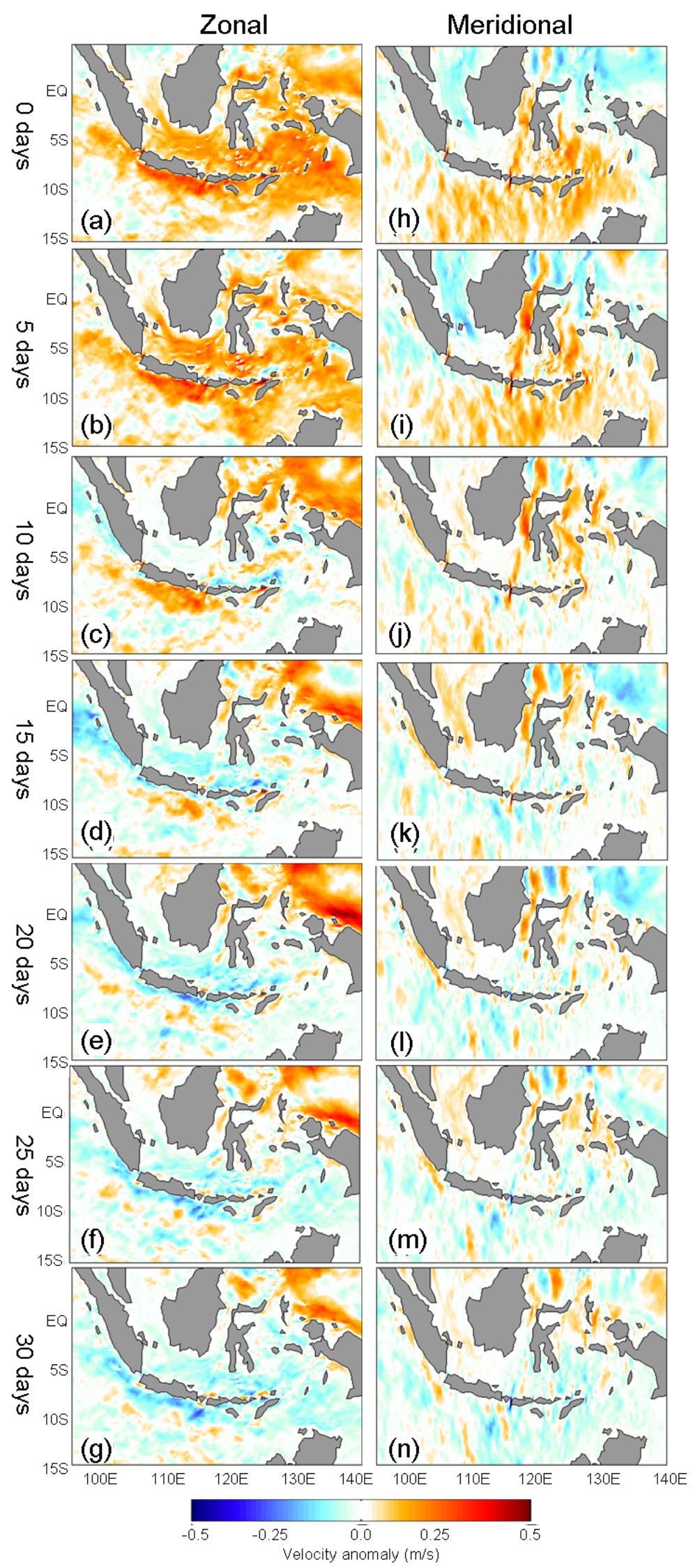

Figure 18: Composites of (a-g) zonal and (h-n) meridional velocity anomalies at depth of $\mathrm{z}=5 \mathrm{~m}$ for positive intraseasonal event. Day 0: peak of positive wind stress anomalies in ITF box marked in Fig. 1. The colour scheme saturates at $\pm 0.5 \mathrm{~m} / \mathrm{s}$. 

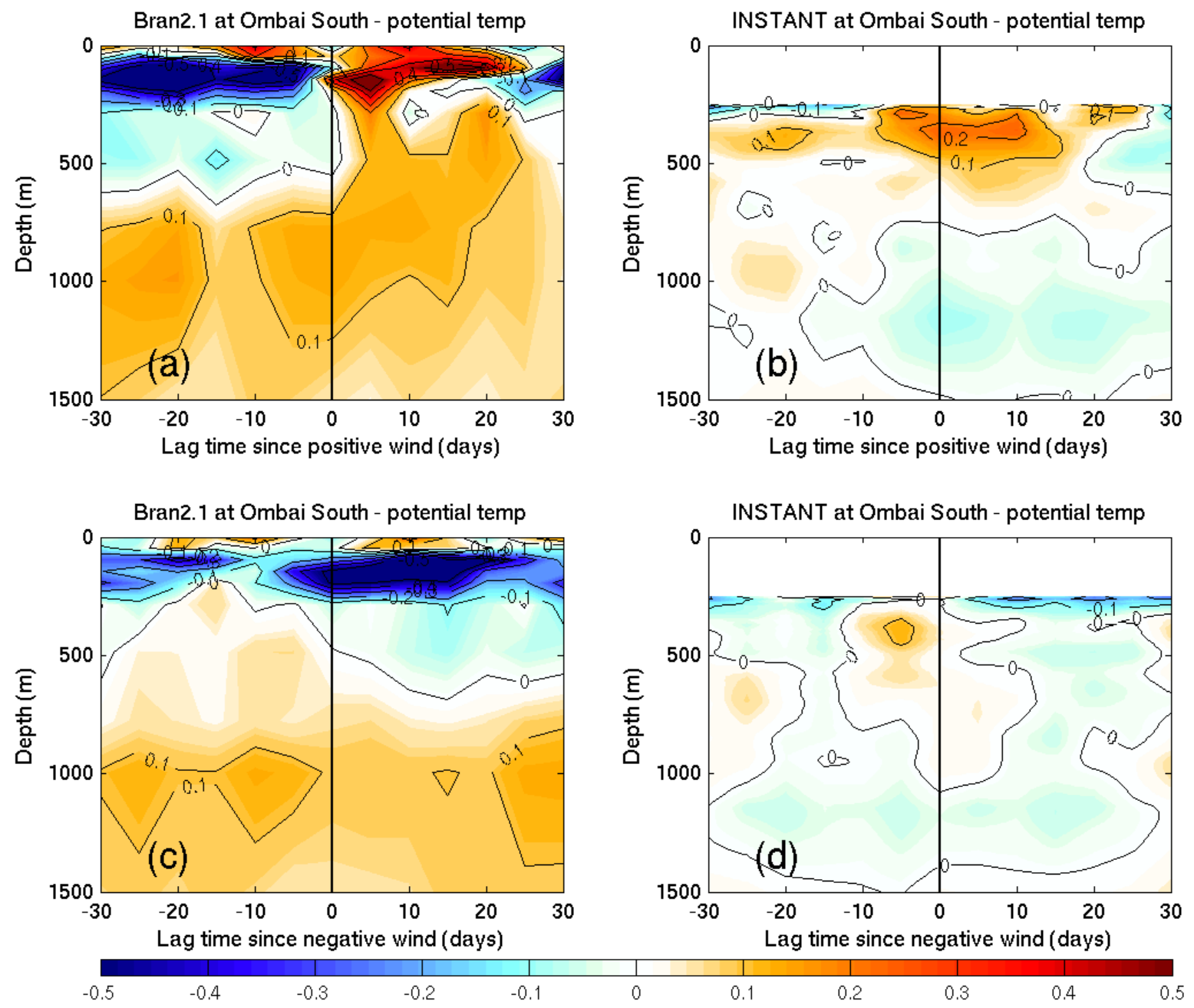

Figure 19: Time-depth plots of composites of potential temperature anomalies at mooring Ombai South for $(a, c)$ BRAN2.1 and $(b, d)$ observations. Day 0: peak of negative and positive wind stress anomalies in ITF box shown in Fig. 1. The colour scheme saturates at $\pm 0.5^{\circ}$ C. C.I.: $0.1{ }^{\circ}$ C. Note missing near-surface data in observations. 

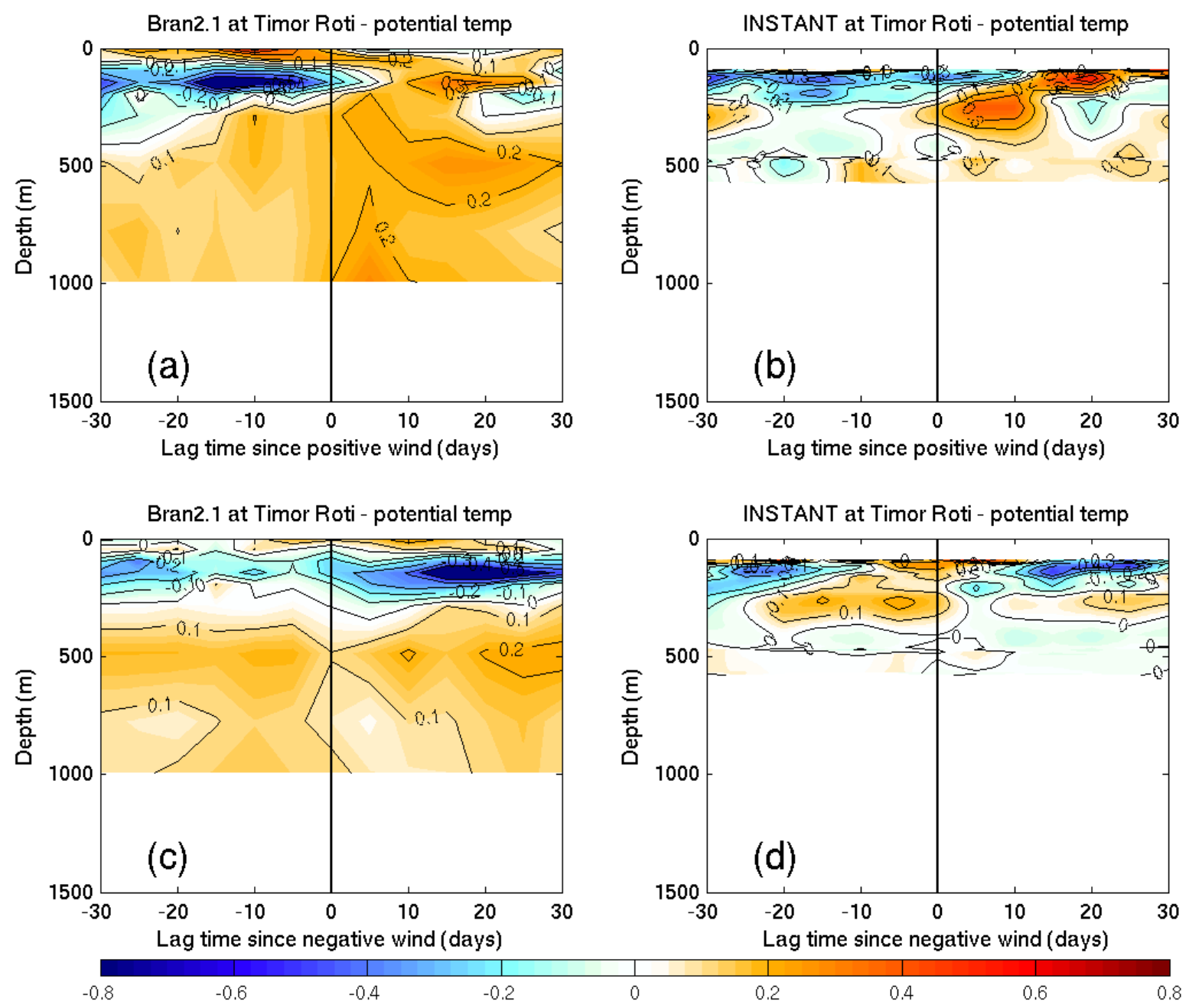

Figure 20: Time-depth plots of composites of potential temperature anomalies at mooring Timor Roti for $(a, c)$ BRAN2.1 and $(b, d)$ observations. Day 0: peak of negative and positive wind stress anomalies in ITF box shown in Fig. 1. The colour scheme saturates at $\pm 0.5^{\circ}$ C. C.I.: $0.1{ }^{\circ}$ C. Note missing nearsurface data in observations. 